\title{
Mixed Methods Review of A Home-Grown School Feeding Pilot in A Poor Ethnic Minority Community in Vietnam
}

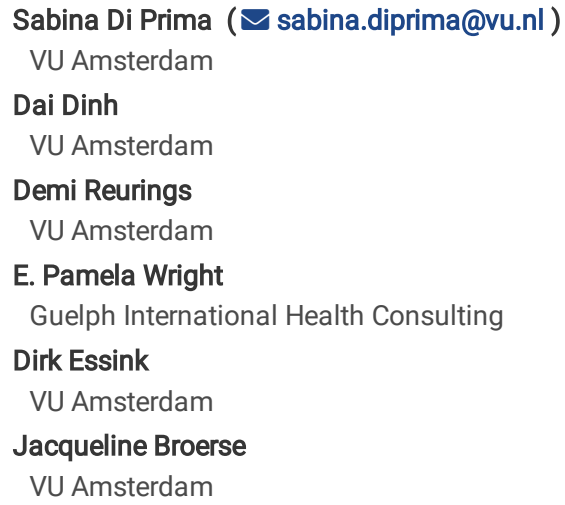

Research Article

Keywords: Nutrition-sensitive agriculture, remote areas, preschool, school meal diversity, social entrepreneurship.

Posted Date: January 29th, 2021

DOl: https://doi.org/10.21203/rs.3.rs-150053/v1

License: () (i) This work is licensed under a Creative Commons Attribution 4.0 International License. Read Full License 


\section{Abstract Background}

Undernutrition threatens the health and future of preschool children in disadvantaged ethnic minority communities. Home-grown school feeding (HGSF) in nursery schools could have a positive impact on children's nutrition while creating multiple benefits for the community and local food system. Evidence is lacking on the implementation and sustainability of HGSF as part of multi-sectoral programs in remote areas. This study assessed a HGSF pilot intervention, implemented within a four-year nutrition-sensitive agriculture (NSA) program, in five nursery schools in a mountain ethnic minority community in Vietnam. It aimed to gain insights into the diversity and cost of school meals, food sources, effects on children's nutritional status and on process aspects related to implementation and sustainability, especially HGSF synergy with other NSA program components.

\section{Methods}

Mixed-methods assessment covered school meal diversity and cost; food sources; anthropometric data; and the process, including changes triggered by HGSF, perceived barriers and facilitators to implementation, and prospects for sustainability. Data came from participants selected by purposive sampling for semistructured interviews $(n=30)$ and seven focus group discussions $(n=76)$, and from field observations and transect walks.

\section{Results}

School meals increased daily dietary diversity; meals cost USD $0.65 /$ child/day. About $44 \%$ of the foods used were home-grown. There was an indicative reduction in underweight children, an increase in school attendance, and improvements in food preferences and WASH practices. Parents' caring and feeding practices improved and their willingness to pay for school meals increased. At community level, local food systems became less cash crop-oriented and more self-reliant in production of nutrient-rich foods, contributing to household food security and income generation. Social capital increased. Positive changes were attributed to HGSF and to synergy among NSA program components. Enhanced confidence and motivation, stimulated by role models and change agents, facilitated the process. Socio-economic conditions of poor households and limited resilience to external shocks were barriers that threatened sustainability.

\section{Conclusions}

This study showed that implementing HGSF in a mountain ethnic minority area with a high prevalence of undernutrition benefitted children and their communities, when integrated in a multi-sectoral program that mobilises all stakeholders and stimulates both supply and demand of nutritious food.

\section{Background}

Undernutrition continues to be a public health problem in many countries, especially for young children and women of reproductive age [1,2]. Recent global estimates suggest that 149 million children under five years of age (CU5) are stunted and 49 million are wasted [3]; about 16 million are affected by both stunting and wasting, contributing to increased risk of mortality [2]. In low- and middle-income countries (LMICs), children from disadvantaged ethnic minority groups are often at higher risk; on average their rates of stunting are 2.8 and of wasting six times higher than those of more advantaged peers [1].

The causes and consequences of childhood undernutrition are multidimensional and interrelated [4-6]. Undernutrition in the early stages of life undermines the cognitive and physical development of children with detrimental long-term consequences on their educational, productive and reproductive performance as adults [7-10]. Given its multifaceted nature, the undernutrition problem requires integrated solutions that involve the collaboration among multiple sectors and synergy between nutrition-specific and nutrition-sensitive approaches, to address simultaneously the direct (health and diet) and the underlying (food security, health services, care practices, hygienic living environment) determinants of children's nutritional status [6, 11-13]. Nutrition-sensitive approaches, particularly food-based approaches such as nutrition-sensitive agriculture (NSA), could play an important role by addressing the underlying determinants through context-dependent, non-linear paths [6] with agriculture as the key entry point, collaborating with other sectors such as health and education.

In the past decades, child undernutrition has become a policy priority on national and international agendas, exemplified by the "Decade of Action on Nutrition" and the 2030 Agenda for Sustainable Development [14, 15]. The 2008 Lancet series highlighted the importance of focusing on the 1000-day period between conception and the first 24 months of life, considered a critical window of opportunity to influence the growth and development of a child [4, 10, 16]. However, taking into account the nutrition and development needs of individuals across their life cycle, less critical but still important windows may appear in the following 7000 days, from early childhood [17] to late adolescence [18-20]. In the first 1000 days, the health system is conventionally the main agent for interventions to improve the nutritional status of infants and young children. Later, school-based nutrition programs often focus on primary school children, but preschool programs, in kindergartens or nursery schools, could also be important for children between three and five years [15, 18], who might otherwise be neglected.

Schools can offer a suitable environment for the promotion and development of healthy eating habits [21]. They can stimulate changes in children's diet and eating behaviours by providing food and because children spend a lot of time there together [21]. Receiving meals at school could lead to increased school enrolment, attendance and retention [22, 23]. Investing in the formative years at school and pre-school could offer strong returns in adulthood [24].

Furthermore, schools represent an appropriate (complementary) platform for multi-sectoral nutrition-sensitive interventions [25, 26], particularly those targeting children normally beyond the reach of regular school programs, such as ethnic minority children aged $3-5$ in remote communities. 
Globally, school feeding programs provide meals to about 368 million children from pre-primary to secondary school, with a total investment up to USD 75 billion a year, confirming the importance of such programs [26]. Since 2003, an increasing number of governments in LMICs have started sourcing part of the food for school feeding from local farmers, with the additional objectives to improve smallholders' livelihoods, strengthen the resilience of local food systems, promote nutrition-sensitive value chains, and reduce food waste [15]. This approach, labelled home-grown school feeding (HGSF), facilitates the transition from external donor-driven to sustainable country/community-owned school feeding programs [27]. It is also promoted as a suitable strategy towards the achievement of several sustainable development goals [15]. HGSF potentially offers context-appropriate solutions by providing school children with nutritious meals that fit local taste preferences [15] and food production [28]. Linking school feeding to local food production systems can help create a stable and structured market for local farmers, traders and caterers in the school feeding supply chain [15]. Decentralizing food procurement to community caterers, as social micro-enterprises, may increase community involvement and support, which can be important for sustainability [15]. Because social entrepreneurship focuses on the potential of individuals and communities rather than on external help [29], it fits the needs in remote and hard-to-serve areas.

To our knowledge, lessons from the implementation of HGSF in nursery schools are still lacking. Existing studies focus mostly on primary schools [30-33]. HGSF can be implemented in the context of a comprehensive package of multisector interventions addressing multiple needs [15]. However, as Reinhardt and Fanzo [6] remarked about the inclusion of nutrition-sensitive interventions in larger multi-sectoral programs, little is known on how HGSF components contribute to and interact with other interventions in complex NSA programs [32]. Questions regarding benefits and costs of HGSF programs [32] and their implementation and sustainability in mountainous areas, are yet to be answered.

These knowledge gaps and the role of HGSF in addressing undernutrition among CU5 are particularly relevant in the context of countries such as Vietnam, with rapid economic development, but where the significant improvements in reducing undernutrition are not distributed equally in the population [34]. In Vietnam, disadvantaged ethnic minority communities in isolated mountainous areas are most affected [35]; their undernutrition is exacerbated by a complex mix of agro-ecological, socio-economic and cultural factors $[34,36,37]$. Ethnic minority CU5 are greatly affected, having higher rates of stunting (31.4\%) and underweight $(21 \%)$ than ethnic majority Kinh children (15\% stunted; $8.5 \%$ underweight) $[34,38]$. The social and economic relevance of undernutrition is evident - ethnic minority groups constitute $14 \%$ of the Vietnamese population or about 13.5 million people [34].

To contribute to the evidence base on HGSF, this study assessed the experience of a HGSF pilot intervention, part of a four-year NSA program, in five nursery schools in a mountain ethnic minority community in Vietnam. It aimed to gain insights into the diversity and cost of school meals, the food sources, and the effect on children's nutritional status, as well as process aspects related to implementation and sustainability, with attention to the synergy between HGSF and other components of the NSA program.

\section{Methods}

\section{Intervention and study setting}

Through two consecutive National Nutrition Strategies (2001-2010 and 2011-2020), the Vietnamese Government has prioritised disadvantaged areas and groups at high risk, promoting multi-sectoral and community-based initiatives, including nutrition programs in nursery schools, and taking a preventive approach, "Nutrition throughout the Lifecycle" [39, 40]. Aligned with this approach and the national action plan "Zero Hunger by 2025", a four-year NSA program was implemented in the mountainous commune of Phu Mo, Dong Xuan district, the most remote and poor commune in Phu Yen province. Box 1 gives a synthetic description of the situation in Phu Mo commune prior to beginning the NSA program. 
Box. 1 Phu Mo Commune Baseline Situation

The data reported below comes from the baseline study conducted by the NSA program in Phu Mo commune in March 2018, collected from a sample of 224 households (unless otherwise indicated).

- Based on the Food Insecurity Experience Scale, among the households surveyed, $13 \%$ were food secure, $42 \%$ mildly food insecure, $39 \%$ moderately, and $6 \%$ severely;

- Among all CU5 $(\mathrm{n}=243), 43 \%$ were underweight and $61 \%$ were stunted;

- $87 \%$ of the households relied on labour as hired farmer, planting and harvesting cassava and acacia;

- Cash-crop production played a central role; $46 \%$ of households earned income from cassava; with a fluctuating price over time but steadily declining since 2012

- Many households grew rice in wet paddy (33\%) or upland (31\%) fields; $96 \%$ of rice production was for own consumption;

- About half of households raised chicken for meat; with 4 chickens per household on average;

- Home gardens were not very common and often used for planting tobacco (40\% of the households). Only $6 \%$ of households planted mustard greens, and only two months/year. Few households grew gourds or banana plants. Most families cultivated eggplants all year round in cassava or upland rice fields;

- Phu Mo commune relied almost entirely on external food supplies. Apart from rice, $88 \%$ of households purchased foods for daily intake, mostly from mobile vendors. About $52 \%$ of households gathered wild foods from the forest, such as vegetables, mushrooms and rats;

- The types of foods purchased from mobile vendors or markets in Dong Xuan District or nearby communes were: fish, meat and eggs (87\% of households), vegetables (79\%), sugar and salt (78\%), rice, as their production was not sufficient (63\%), and milk (30\%);

- Local shops sold mostly dried and packaged foods such as instant noodles, porridge and snacks;

- The local diet generally consisted of rice, cassava leaves, wild vegetables, chili and salt;

- According to the 24-hour recall in all CU5 of Phu Mo communes ( $n=243)$, most had consumed only one ( $24 \%$ of children) or two food groups ( $60 \%$ ), predominantly grains, over 24 hours. Less than $5 \%$ of all CU5 had a combined consumption of 'starchy staples', 'meat and fish', 'fruits and vegetables' and 'dairy products' over 24 hours;

- Until the school year 2017-2018, none of the nursery schools in Phu Mo provided meals; in Dong Xuan district 15 of the 16 nursery schools in ethnic minority villages did not provide meals;

- In the school year 2017-2018, average daily attendance was $88 \%$ (attendance is compulsory);

- At the time of the baseline, there were no Government or NGO program/projects on-going or just completed. The NSA program was the first initiative in Phu Mo.

The NSA program has been implemented from 2017-2020., with the aim of reducing stunting and underweight among ethnic minority CU5 by improving food access and food intake. The Medical Committee Netherlands-Vietnam (MCNV), in partnership with Dong Xuan district and Phu Yen province, set up this action-research program with funding from the Netherlands Organisation for Scientific Research and the co-contribution of the local government. Scientific guidance was provided by Hue University of Agriculture and Forestry, Hue University of Medicine and Pharmacy and the Vrije Universiteit Amsterdam. The NSA program involved three programmatic sectors - agriculture, education and health - and multiple entry points - community, households and nursery schools. All sectors contributed to the design and implementation of the integrated intervention package, while each sector took responsibility for coordinating and monitoring specific components. Assessment of progress and improvement of design based on monitoring results was a joint undertaking. The agriculture sector developed context-appropriate agricultural models aimed at supporting households with CU5 to plant nutrient-rich vegetables and fruit and raise chickens and quail, thus partially shifting from cash crops, to improve daily food intakes. The health sector enhanced behavioural change in child care and feeding by training household groups on nutrition, cooking, feeding and monitoring growth of CU5. The education sector cooperated with local food microenterprises to develop the home-grown school feeding (HGSF) component.

The main objective of the HGSF program was to reduce undernutrition among nursery school children (48-59 months old) from $30 \%$ in 2018 to $10 \%$ in 2020 by providing nutritious school meals to the five nursery schools in Phu Mo. Through this component, the NSA program aimed to change the supply chain of nutritious foods in these mountain villages by stimulating local production and demand. Four local micro-enterprises were established to prepare the meals; one covered schools in two nearby villages (Phu Giang and Phu Loi), while the others served the remaining three schools. The micro-entrepreneurs were all women who could cook and wished to trade in nutritional products for nursery schools and the community. These skilled, motivated and local entrepreneurs were supported by the Health Centre and the Department of Education and Training to build good knowledge and practice on food preparation, hygiene and food safety. The micro-entrepreneurs were also provided with basic facilities, such as refrigerators, food containers, blenders and rice cookers. Menus were adapted from the national school menu guidelines issued by the Ministry of Education to fit local factors, such as seasonality, availability of ingredients, food preferences, and cultural aspects. The menus were developed for one month, with repetition in first and third and in second and fourth weeks. Seasonal or unavailable components could be replaced; the micro-entrepreneurs informed the head of the nursery school and changed the meal composition to ensure a balanced diet. The micro-entrepreneurs relied upon a mixture of home-grown (own-production and local farmers) and external (district market and mobile vendors) sources to procure the ingredients.

Each nursery school assigned one teacher to monitor the appropriate supply of the daily menus and the correct substitution of unavailable ingredients. To ensure safe feeding practices, nursery school teachers received training on nutrition, feeding and WASH practices by the Department of Education and Training. In turn, teachers trained the mothers volunteering to help with feeding and caring for children on these topics, emphasising hand-washing and cleaning utensils. The overall monitoring of the HGSF program was the responsibility of the District Education Department, the nursery school principals and the teachers. Regular meetings were organised among micro-entrepreneurs, teachers, parents and program implementers to discuss progress and challenges regarding the school meals. 
Nursery school children received school meals on weekdays, starting with only breakfast, from March 2018. However, the staggered entry program design meant that not all schools started providing meals in the first year (see Fig. 1). It should be noted that from September 2019 each child also received $180 \mathrm{ml}$ of milk three days/week under a school milk program launched by the provincial government - an unforeseen but valuable addition to boost their nutritional status.

To promote community buy-in, the NSA program subsidised a one-month pilot, after which payments were introduced, at first $33 \%$, increasing to $59 \%$ in January 2020; from 2021 they will cover the full cost. For the poorest households (at or below 1.90 USD per capita), the government subsidizes 149,000 VND (about USD 6.43) per month for school meals (45\% of costs) and 100,000 VND (about USD 4.31) per month for school supplies; the subsidy is disbursed twice a year. Teachers received an allowance from the project for their extra work (500,000 VND/month; USD 21.51). The micro-entrepreneurs were also paid for their labour (100,000 VND/day; USD 4.30), which was covered by the price of the school meals.

\section{Study design}

A mixed-methods assessment of the HGSF intervention included meal diversity as a proxy for intake of diverse, nutritious meals by nursery school children. The assessment further comprised an analysis of food sources used for the school meals, to gauge the extent of the "home-grown" dimension of the intervention, and a cost analysis. Anthropometric data provided by the school monitoring system was reviewed to obtain an indicative measure of the impact on the nutritional status of the nursery school children. Lastly, process-related aspects were reviewed using qualitative methods, focusing on changes triggered by the HGSF intervention, observed barriers and facilitators, and factors related to sustainability, such as perceived challenges and potential strategies to sustain the interventions after the NSA program. In the framework of this study, observed changes refer to key outcomes (such as increased school attendance) and impacts (children's improved nutritional status) that in the perception of the participants stemmed from the HGSF intervention in synergy with the other NSA program components. The terms facilitators and barriers refer to those factors that enabled and/or constrained the implementation of the HGSF intervention. Such factors are usually related to the socio-economic, cultural, bio-physical, political and legislative context in which the interventions are implemented. Contextual factors are less easily influenced and, in the context of an intervention, are often considered as a precondition. However, the level of influence that implementers have on these factors increases if they are internalized as part of the program design, for example, the role models and change agents in this case. The overall methodological approach for this study was largely based on the ex-post evaluation of a HGSF pilot program in Nepal by Shrestha et al. [30] and past experiences with theory-driven process evaluation [41].

The foundation for the qualitative research was an ex-ante program theory of change re-constructed using internal reports of the NSA program and other secondary sources (see Fig. 2). Its design was based on well-known conceptual pathways from agriculture to nutrition [42, 43]. The program theory allowed us to visualise and unpack the primary pathways of change envisaged by the program (production-consumption, caring and feeding, and HGSF) and uncover the synergies emerging across pathways. The program theory informed the design of the data collection tools and the qualitative analysis. The study was approved by the Institutional Ethics Committee of Hue University of Medicine and Pharmacy in Vietnam (registration number H2018/010).

\section{Study population}

The direct beneficiaries of the HGSF program were the children (48-59 months old) attending the five nursery schools of Phu Mo. In the school year 20192020,132 children were registered. In previous school years the numbers were slightly lower (116 in 2018-2019; 118 in 2017-2018, according to Ministry of Education data). Each year, an estimated $45 \%$ of the children registered are attending the nursery school for the first time.

To strengthen the validity of the qualitative findings, the process assessment included a variety of participants from several stakeholder groups at different administrative levels: micro-entrepreneurs, teachers, parents/farmers in the villages, and implementers from the agriculture, education and health departments at three levels. See Table 1 for a complete overview of respondents and tools used. All five villages of Phu Mo commune (Phu Tien, Phu Hai, Phu Giang, Phu Dong and Phu Loi) were included in the thirty semi-structured interviews (SSIs) and seven focus group discussions (FGDs) (total $n=76$ ). Purposive sampling was used to select the participants, with the aim of obtaining views from all types of stakeholders. The main eligibility criterion for implementers in the SSIs and FGDs was to have knowledge of and be involved in all three components of the intervention package (agriculture, health-nutrition and education). Only beneficiaries from households with CU5 and/or pregnant women were eligible for the study; they were selected and invited by the village heads. The FGDs at village level targeted parents, but in fact only women attended, 9 to 18 per village. 
Table 1

Overview of respondents and data collection tools

\begin{tabular}{|c|c|c|c|c|c|}
\hline Level & Respondents & SSls & $\begin{array}{l}\text { SSIs } \\
\text { participants }\end{array}$ & FGDs & $\begin{array}{l}\text { FGDs } \\
\text { participants }\end{array}$ \\
\hline $\begin{array}{l}\text { Implementing } \\
\text { NGO }\end{array}$ & Chief of office and lead implementer & 1 & 1 & - & - \\
\hline District & Lead implementers from agriculture, health and education departments & 3 & 3 & 1 & 7 \\
\hline Commune & $\begin{array}{l}\text { Principal of Phu Mo nursery schools, health station representative, agriculture } \\
\text { extension staff }\end{array}$ & 3 & 3 & 1 & 5 \\
\hline \multirow[t]{4}{*}{ Village } & Village health workers (VHW) & 5 & 5 & - & - \\
\hline & Nursery school teachers & 5 & 5 & - & - \\
\hline & Micro-entrepreneurs & 4 & 4 & - & - \\
\hline & Parents/farmers (across the five villages) & 9 & 9 & 5 & 64 \\
\hline Total & & 30 & 30 & 7 & 76 \\
\hline
\end{tabular}

\section{Data collection and analysis}

\section{Assessment of school meal diversity}

In the context of this study, school meal diversity was used as a proxy for dietary diversity among nursery school children. To assess the diversity of the summer and winter school meals, breakfast and lunch menus were categorized into nine food groups, according to the FAO Guidelines for Measuring Household and Individual Dietary Diversity [44], as used previously in Asia [45]. The nine food groups were: starchy staples, dark green leafy vegetables, vitamin A rich fruits and vegetables, other fruits and vegetables, meat and fish, eggs, organ meat, legumes, nuts and seeds, and dairy products. The Department of Education and Training provided the weekly summer and winter menus, which included the number of children to be served at each school, the ingredients for each meal, and the quantity of each ingredient needed for that number of children. For the school meal diversity, two alternating weekly menus, adapted for summer and winter, were scored separately. From these four menus, average percentages of food groups were calculated. Inter-food group diversity, the number of food groups, was assessed by assigning one point to any individual food item in each food group in one meal (breakfast or lunch). Different individual food items in the same group were not counted again. School meal diversity scores ranged from 0 to 9 (higher score $=$ greater diversity). The results of the inter-food group diversity were then compared with the baseline 24-hour recall for CU5 in the NSA program (2018) to gain insights on the contribution of school meals to dietary diversity among nursery school children. Counting food groups in a meal did not consider minimum quantity requirements per food group. The intra-food group diversity, the number of unique individual foods within a food group, was also calculated separately for breakfast and lunch meals.

\section{Assessment of food sources}

Data on the sources of food used to prepare the meals were collected from each micro-entrepreneur in July 2020. Information was gathered on the percentage of 'rice', 'vegetables \& fruits', 'fish, pork and beef', 'chicken and quail eggs' and 'chicken meat' procured from local farmers, own production, mobile vendors, and district market. The first two sources were combined in the category 'home-grown' while the latter two were categorised as 'external'. An overview of food categories per source was developed for each village and all villages combined.

\section{Assessment of school meal costs}

Data on school meal costs were provided by the Department of Education and Training. They included the cost per ingredient for each breakfast and lunch, gas for cooking and the cook's wage. These costs were cross-checked with the expenses reported by the micro-entrepreneurs and the payments they received for their services. The cost of training micro-entrepreneurs and teachers was not included. Transportation costs were minimal as the micro-entrepreneurs were located near the schools. The average cost per meal per child was calculated by dividing the total meal cost (summer and winter meals separately) by the number of actual feeding days, and the average number of students attending the nursery school.

\section{Anthropometrics}

Teachers measure child growth thrice annually, in the middle of September, December and March (May for 2019-2020 due to COVID-19), as regulated by the Ministry of Education and Training. The data included sex, date of birth, weight $(\mathrm{kg})$, and height $(\mathrm{cm})$. All teachers received training on anthropometric measurements as part of an annual refresher course. The Phu Mo nursery schools weighed the children on a Tanita digital scale designed for children, accurate to $0.1 \mathrm{~kg}$. For height, they used a tapeline with an accuracy of $0.5 \mathrm{~cm}$., in standing position, barefoot. Teachers used WHO Z-score charts to calculate nutritional status. Children whose weight-for-age Z-score (WAZ) was below - 2 standard deviations (SD) from the median of the WHO reference population were considered underweight. In the context of this study, these anthropometric data, collected routinely, were used as secondary data, which provided an indicative measure of the impact of the school meals on the nutritional status of the nursery school children.

\section{Qualitative process assessment}

Qualitative data was collected between April and July 2020 using tools developed in English, translated into Vietnamese and checked for cultural appropriateness by MCNV staff. SSIs and FGDs were conducted by a facilitator experienced in participatory data collection, with the assistance of a District Health staff member. Due to COVID-19 restrictions, some interviews were conducted remotely and video-recorded. All FGDs and the majority of the SSIs at 
village level were conducted in person and audio-recorded. Informed consent and permission to record interviews were obtained from each respondent. Data from SSIs and FGDs were first transcribed verbatim into Vietnamese then translated into English. The quality and fidelity of transcriptions were checked by two local members of the research team against the audio/video records.

SSI guides were designed using themes relevant to the ex-ante program theory of change (Fig. 2) and taking into account elements of social entrepreneurship intention models, such as attitude towards becoming a social entrepreneur, self-efficacy, emotional empathy and social support [46], for aspects related to the micro-entrepreneurs. The SSI guides were tailor-made for each stakeholder group and addressed process (changes stimulated by the HGSF intervention, perceived barriers and facilitators) and sustainability-related aspects (challenges and strategies). A pilot test of the interview guide was run, to improve fitnessto-purpose and duration. Interviews lasted approximately 60 minutes on average. They were organized in an iterative process; starting with district level, then commune and village level, while results were continually integrated with previous insights. SSIs continued until saturation of data was reached and no new information emerged.

FGDs were scheduled after all SSIs were completed to validate preliminary findings, to obtain deeper insights into frequently-appearing themes, and to gain further lessons from different perspectives. The FGD tools consisted of open-ended questions and visual prompts to facilitate interaction. For example, the commune and district level tool used the ex-ante program theory of change to validate/refine the primary pathways (production-consumption, caring and feeding, and HGSF) and identify synergies across pathways. It also helped stimulate inter-sectoral discussion on outcomes of the interventions, barriers and facilitators to implementation, home-made solutions to address barriers, and strategies to sustain interventions, with specific focus on HGSF. A simplified version of the tool was used for the FGDs at village level, where real-life pictures from Phu Mo facilitated discussions on intervention activities, perceived changes, how and why they occurred, and factors influencing those changes. Special emphasis was given to challenges and strategies for HGSF sustainability, especially regarding inclusion of the most vulnerable households. FGDs at village level lasted about 60 minutes and involved parents whose children benefited from the school meal program; some were also farmers supplying food to the local micro-entrepreneurs. FGDs at commune and district level had fewer participants and lasted longer (1.5-2 hours).

Several strategies were implemented to enhance the validity of qualitative findings: notes of the SSIs and FGDs were taken and, if time allowed, verified with the participants after each session. Interview summaries were used for member checking while district and commune meetings helped with collective validation of FGDs findings. The results of the qualitative process assessment were triangulated with findings of the field observations and transect walks conducted regularly (every month except for the COVID quarantine period) by MCNV staff and District staff from agriculture, health and education.

The English transcripts were summarized, coded and analysed using Atlas.ti 8.4.4 Mac. The ex-ante program theory of change (Fig. 2) helped to structure the horizontal content analysis. A codebook was created through an iterative process; the central themes were identified deductively while the code list was generated inductively. The thematic analysis was informed by the principles for qualitative data analysis by Bazeley [47]. Initially, one of the researchers independently and systematically coded the SSIs and FGDs, then the other authors reviewed the original data and discussed code attribution to reach consensus. While the findings reported in this study reflect the perspectives of the different stakeholders, specific quotations are used to illustrate key points.

\section{Results}

In the first part of the results, we analyse the meals served to the children and the results of their improved nutrition as well as the cost of school meals and the sources of foods. In the second part, we report the perceptions and expectations of different stakeholders arising during the SSIs and FGDs.

\section{School meal diversity}

Four weekly menus (two for summer and two for winter) were analysed. In terms of inter-food group diversity, on average, a lunch menu contained 3-4 food groups and to 2-3 in breakfasts (Fig. 3). 'Starchy staples' and 'meat and fish' were the most frequently consumed food groups at both meals in both seasons. As for intra-food group diversity, lunch menus also had greater diversity within each food group, containing on average one more individual type of food per group than breakfast. For example, while lunch menus included chicken, shrimps and pork from the group 'meat and fish', breakfasts comprised only chicken and shrimps. The greater inter- and intra-food group diversity of lunch meals was partly attributed to local culture, which considers lunch the most important meal of the day. Children's dietary diversity, thanks to the school meals, considerably improved over the situation recorded at baseline (see Box 1 ).

\section{School meal food sources}

The overview of food sources used by micro-entrepreneurs to procure ingredients for school meals in each village are presented in Fig. 4. The 'home-grown' category includes food obtained from local farmers and micro-entrepreneurs' own production, while external sources are mobile vendors and the district market. The micro-entrepreneurs supplying meals to Phu Tien and the adjacent villages of Phu Giang and Phu Loi used home-grown food the most. Similarly to the situation at the onset of the NSA program, rice was most frequently obtained from home-grown sources (65\% on average across all villages). Thanks to the increased local availability of nutritious foods, the "home-grown" dimension of the school feeding component grew larger over the program duration. On average, $43.7 \%$ of the foods used for school meals were home-grown, reflecting procurement choices of the two micro-entrepreneurs catering for Phu Tien, Phu Giang and Phu Loi. As of July 2020, on average $40 \%$ of chicken meat and $20 \%$ of eggs were obtained from local farmers. Furthermore, the same two micro-entrepreneurs reported purchasing $40 \%$ of vegetables and fruits from home-grown sources. The foods least frequently obtained from home-grown production were fish, pork and beef; in Phu Hai and Phu Dong they were bought exclusively from external sources.

\section{School meal costs}

The estimated total school meal cost was about VND 15,000/child/day (USD 0.65), equivalent to $10 \%$ of the daily payment for hired farm labour. The average cost for breakfast was VND 5,048 (USD 0.22) during summer and VND 4,934 (USD 0.21) during winter; lunches cost VND 10,000 (USD 0.43 ) in both seasons. 
Because parents paid a standard amount of VND 15,000/child/day (including the NSA program subsidy), equal to the cost of the two meals, the microentrepreneurs did not make any profit; their expenses and earnings for the meals were the same.

\section{Anthropometrics}

Table 2 shows the aggregated underweight percentages of the boys and girls in the five nursery schools over three years, based on the measurements taken at school. The comparatively high underweight percentages at the beginning of each school year reflect that about $45 \%$ of the children are newly-registered each September, and students from the previous year have not benefitted from nutritious school meals during the three-month summer holiday. During the school year 2017-2018, the school meal program had not fully started. Breakfast was piloted in Phu Tien and Phu Giang for a few months starting from March 2018, so that the March measurements were not affected. In 2017-2018, there was little difference in the proportion of underweight children between the beginning and the end of the school year. However, for the school year 2018-2019, the proportion of underweight children was reduced from 26-14\% by the end of the school year. Already in the December measurement, there was a trend of increasing weight among the children, although not yet enough to bring the children above the level of 'underweight'. The impact of the HGSF intervention in its second period (2019-2020) was observed in the first part of the school year, before schools closed because of COVID-19. The proportion of underweight children decreased by $16 \%$ between the start of school in September and the December measurements, in all villages.

Table 2

Overview of respondents and data collection tools

\begin{tabular}{|c|c|c|c|c|c|c|c|c|c|c|}
\hline \multirow{2}{*}{$\begin{array}{l}\text { School } \\
\text { Year }\end{array}$} & \multirow{2}{*}{$\begin{array}{l}\text { Children } \\
\text { registered } \\
\text { at five } \\
\text { nursery } \\
\text { schools }\end{array}$} & \multicolumn{3}{|l|}{ September } & \multicolumn{3}{|l|}{ December } & \multicolumn{3}{|c|}{ March (May for 2019-2020) } \\
\hline & & $\begin{array}{l}\text { Male } \\
\text { children } \\
\text { underweight }\end{array}$ & $\begin{array}{l}\text { Female } \\
\text { children } \\
\text { underweight }\end{array}$ & $\begin{array}{l}\text { Aggregated } \\
\text { underweight }\end{array}$ & $\begin{array}{l}\text { Male } \\
\text { children } \\
\text { underweight }\end{array}$ & $\begin{array}{l}\text { Female } \\
\text { children } \\
\text { underweight }\end{array}$ & $\begin{array}{l}\text { Aggregated } \\
\text { underweight }\end{array}$ & $\begin{array}{l}\text { Male } \\
\text { children } \\
\text { underweight }\end{array}$ & $\begin{array}{l}\text { Female } \\
\text { children } \\
\text { underweight }\end{array}$ & $\begin{array}{l}\text { Aggre } \\
\text { unden }\end{array}$ \\
\hline 2017- & 118 & 16 & 12 & $24 \%$ & 16 & 12 & $24 \%$ & 15 & 11 & $22 \%$ \\
\hline 2018 & $\begin{array}{l}(65 \mathrm{M} ; \\
53 \mathrm{~F})\end{array}$ & & & & & & & & & \\
\hline 2018- & 116 & 13 & 17 & $26 \%$ & 14 & 16 & $26 \%$ & 6 & 10 & $14 \%$ \\
\hline $2019 *$ & $\begin{array}{l}(64 \mathrm{M} ; \\
52 \mathrm{~F})\end{array}$ & & & & & & & & & \\
\hline 2019- & 132 & 21 & 22 & $33 \%$ & 12 & 10 & $17 \%$ & 17 & 17 & $26 \%$ \\
\hline 2020 & $\begin{array}{l}\text { (68M; } \\
64 \mathrm{~F})\end{array}$ & & & & & & & & & \\
\hline
\end{tabular}

* In 2018-2019, the village of Phu Hai did not benefit from school meals, while Phu Dong benefitted only from February 2019 , only 1.5 months before anthropometric measurements were taken in mid-March. If these two villages are removed from the calculation, the following percentages of aggregated underweight apply: 22\% in September 2018; 22\% in December 2018; and 12\% in March 2019.

\section{Qualitative process assessment}

The results of the thematic analysis are structured as follows. Firstly, we present the most important changes observed among children, parents and the community that, in the perceptions of the different stakeholders, were stimulated by the HGSF intervention. Secondly, we report the perceived barriers and facilitators encountered in the implementation process. Lastly, we describe the sustainability challenges and strategies put forward by the respondents to overcome them. An overview of perceptions across stakeholders is presented in Table 3 . While the different stakeholders were in general agreement about the changes, barriers and facilitators and prospects for sustainability, each group had their own vision according to their role in the program. 
Table 3

Perceptions across different stakeholders

\begin{tabular}{|c|c|c|c|}
\hline $\begin{array}{l}\text { Stakeholder } \\
\text { group }\end{array}$ & Perceived changes & Barriers and facilitators & Sustainability \\
\hline All & $\begin{array}{l}\text { - Reduced undernutrition } \\
\text { - Increased school attendance } \\
\text { - Improved caring and feeding by parents } \\
\text { - Increased social capital } \\
\text { - Established willingness to pay school meals }\end{array}$ & $\begin{array}{l}\text { - Role models, change agents and } \\
\text { knowledge sharing opportunities } \\
\text { instrumental in process of change } \\
\text { - Poverty is the main barrier }\end{array}$ & $\begin{array}{l}\text { - Willingness to maintain school feeding } \\
\text { program } \\
\text { - Limited ability to pay of the poorest } \\
\text { families } \\
\text { - Financial risks depending on } \\
\text { government and other funding } \\
\text { - Lack of resilience to shocks like COVID- } \\
19\end{array}$ \\
\hline $\begin{array}{l}\text { District } \\
\text { authorities }\end{array}$ & $\begin{array}{l}\text { - Caring and feeding practices by families improved } \\
\text { (health and education) } \\
\text { - Local food system: more balance between cash } \\
\text { crops and non-cash crops and increased food } \\
\text { availability (health and agriculture) }\end{array}$ & $\begin{array}{l}\text { Facilitators } \\
\text { - Role models enhanced confidence } \\
\text { (all) } \\
\text { - Influential people used to educate } \\
\text { (health and education) } \\
\text { - Children request same food at } \\
\text { home (health) } \\
\text { Barriers } \\
\text { - Irregular cash income and lack of } \\
\text { time (all) }\end{array}$ & $\begin{array}{l}\text { Challenges } \\
\text { - HGSF sustained if government keeps } \\
\text { existing subsidy policies (education and } \\
\text { agriculture) } \\
\text { - COVID halted HGSF implementation } \\
\text { (education) } \\
\text { Strategies } \\
\text { - Tailor-made payments, support from } \\
\text { charity groups, for poorest households } \\
\text { (all) } \\
\text { - Social entrepreneurship: } \\
\text { HGSF sustainable if micro-enterprises } \\
\text { continue to thrive (health) } \\
\text { - Reduce reliance on program support } \\
\text { (health) }\end{array}$ \\
\hline $\begin{array}{l}\text { Commune } \\
\text { authorities }\end{array}$ & $\begin{array}{l}\text { - Parents have more knowledge on nutrition and } \\
\text { more concerned for children } \\
\text { - Increased home-grown food supply } \\
\text { - Increased food availability and food intake at } \\
\text { household level } \\
\text { - Shift from buying food with wages to producing } \\
\text { own food and selling surplus } \\
\text { - Household groups and school meetings enhanced } \\
\text { social capital }\end{array}$ & $\begin{array}{l}\text { Facilitators } \\
\text { - Role models and participation of } \\
\text { villagers from beginning built } \\
\text { confidence } \\
\text { - Selection of active/committed } \\
\text { micro-entrepreneurs } \\
\text { - Exposure visits for knowledge } \\
\text { sharing } \\
\text { Barriers } \\
\text { - Irregular cash income and lack of } \\
\text { time }\end{array}$ & $\begin{array}{l}\text { Challenges } \\
\text { - Difficult for some parents to pay full } \\
\text { cost } \\
\text { - During COVID-19 undernutrition rates } \\
\text { returned to previous high levels } \\
\text { Strategies } \\
\text { - Encourage parents' contribution to } \\
\text { sustain school meals } \\
\text { - Semi-boarding school approach } \\
\text { - Social support networks: community } \\
\text { members help each other } \\
\text { - Increase support for more local micro- } \\
\text { enterprises } \\
\text { - Request District to provide more } \\
\text { training and materials on NSA }\end{array}$ \\
\hline $\begin{array}{l}\text { Village health } \\
\text { workers }\end{array}$ & $\begin{array}{l}\text { - Parents bring children to school more regularly } \\
\text { - Children change eating behaviour at school } \\
\text { - Parents spend more money on food for children } \\
\text { - Households with sufficient water have enough } \\
\text { nutritious food for children } \\
\text { - Household groups meetings enhanced social } \\
\text { capital }\end{array}$ & $\begin{array}{l}\text { - Role models enhanced confidence: } \\
\text { seeing results motivates people } \\
\text { - Eating with peers motivates } \\
\text { children } \\
\text { Barriers } \\
\text { - Irregular cash income and lack of } \\
\text { time } \\
\text { - Lack of knowledge and awareness }\end{array}$ & $\begin{array}{l}\text { Challenges } \\
-60-70 \% \text { of parents are willing and able } \\
\text { to pay the full cost of school meals but } \\
\text { not the poorest } \\
\text { Strategies } \\
\text { - More training needed on NSA topics }\end{array}$ \\
\hline
\end{tabular}




\begin{tabular}{|c|c|c|c|}
\hline $\begin{array}{l}\text { Stakeholder } \\
\text { group }\end{array}$ & Perceived changes & Barriers and facilitators & Sustainability \\
\hline \multirow{9}{*}{$\begin{array}{l}\text { Nursery } \\
\text { school } \\
\text { teachers }\end{array}$} & - Children attend school more regularly and on time & Facilitators & Challenges \\
\hline & $\begin{array}{l}\text { - Children changed hygiene habits and food } \\
\text { preferences }\end{array}$ & $\begin{array}{l}\text { - Micro-entrepreneurs monitor child } \\
\text { needs and improve meals }\end{array}$ & $\begin{array}{l}\text { - Paying full cost of school meals will be } \\
\text { a challenge }\end{array}$ \\
\hline & - Parents spend more money on food for children & - Micro-entrepreneurs provide & - Home feeding not yet of sufficient \\
\hline & - School meals made using local food & poor families & during COVID-19 lockdown) \\
\hline & $\begin{array}{l}\text { - Increased communication among teachers, } \\
\text { parents and micro-entrepreneurs }\end{array}$ & $\begin{array}{l}\text { - Teachers have opportunities to } \\
\text { advise parents on children's health } \\
\text { and on cooking nutritious food }\end{array}$ & $\begin{array}{l}\text { - Teachers motivated by program } \\
\text { support (allowance) }\end{array}$ \\
\hline & & 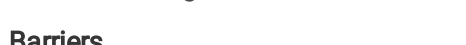 & Strategies \\
\hline & & $\begin{array}{l}\text { - Lack of money (especially in rainy } \\
\text { season) and time reduces parents' } \\
\text { participation }\end{array}$ & $\begin{array}{l}\text { - Semi-boarding school approach also } \\
\text { for younger children; more time for } \\
\text { parents to work }\end{array}$ \\
\hline & & $\begin{array}{l}\text { - Parents working away unable to } \\
\text { take good care of children }\end{array}$ & - Need for Government support \\
\hline & & $\begin{array}{l}\text { - Some parents cannot pay for } \\
\text { school meals on time }\end{array}$ & \\
\hline \multirow{7}{*}{$\begin{array}{l}\text { Micro- } \\
\text { entrepreneurs }\end{array}$} & - Children changed food preferences & Facilitators & Challenges \\
\hline & $\begin{array}{l}\text { - Parents more concerned about their children; } \\
\text { some buy same meals for children not in nursery } \\
\text { school }\end{array}$ & $\begin{array}{l}\text { - Micro-entrepreneurs committed to } \\
\text { improve meals to fit children's needs } \\
\text { and to provide meals for all children }\end{array}$ & $\begin{array}{l}\text { - COVID-19 increased child } \\
\text { undernutrition and affected activities and } \\
\text { businesses }\end{array}$ \\
\hline & $\begin{array}{l}\text { - Parents are willing to pay for school meals, about } \\
\text { half are able to }\end{array}$ & $\begin{array}{l}\text { - Micro-entrepreneurs teach parents } \\
\text { how to prepare meals }\end{array}$ & Strategies \\
\hline & - Local food sources are used for school meals, & Barriers & $\begin{array}{l}\text { - Micro-entrepreneurs will continue } \\
\text { serving meals, and even expand in }\end{array}$ \\
\hline & $\begin{array}{l}\text { diversity than at district market but safer and } \\
\text { cheaper) }\end{array}$ & $\begin{array}{l}\text { - Late payments by parents limit } \\
\text { food procurement by micro- } \\
\text { entrepreneurs }\end{array}$ & their markets \\
\hline & $\begin{array}{l}\text { - Increased trust in the capacity or micro- } \\
\text { entrepreneurs }\end{array}$ & $\begin{array}{l}\text { - Food supply challenges: high } \\
\text { market prices }\end{array}$ & \\
\hline & & $\begin{array}{l}\text { - Poor financial management: } \\
\text { parents not used to save money }\end{array}$ & \\
\hline \multirow{5}{*}{$\begin{array}{l}\text { Parents/ } \\
\text { farmers }\end{array}$} & - Parents have more spare time & Facilitators & Challenges \\
\hline & - Parents pay more attention to children's nutrition & \multirow{2}{*}{$\begin{array}{l}\text { - Peer to peer meetings promote } \\
\text { learning, knowledge sharing and } \\
\text { behaviour change }\end{array}$} & - All want to sustain the school feeding \\
\hline & $\begin{array}{l}\text { - Parents see that children like the food at school; } \\
\text { they get good meals }\end{array}$ & & Strategies \\
\hline & - Increased availability of nutritious food and & Barriers & - Arrange payment scheme with micro- \\
\hline & change in food intake & $\begin{array}{l}\text { - For some, lack of time and } \\
\text { irregular cash income for regular } \\
\text { payment of school meals }\end{array}$ & entrepreneurs \\
\hline
\end{tabular}

\section{Observed changes: children}

The most important changes observed among nursery school children were their increased school attendance and improved nutritional status. Attending school more regularly had an impact on meal frequency and diversity and influenced children's food preferences and hygiene practices.

School attendance - According to Phu Mo nursery school reports, in the school year 2017-2018 the average attendance ratio was $88 \%$, but that increased to $97.6 \%$ in 2018-2019 and $98.6 \%$ in 2019-2020; children stayed home only when sick. Children arrived on time for breakfast and stayed until after lunch: "Before the school meals, children often went home from school at around 10.30 a.m.; the few who had some money would buy candies at local shops but most would eat leftover rice at their parents. They did not have real lunches." (R13, micro-entrepreneur). School meals were an important motivational factor, as observed by District education staff and described by a teacher: "Children changed considerably since this model has been applied. They go to school on time and more regularly" (R8, Teacher). Children enjoyed the taste of the school meals, as proudly reported by several micro-entrepreneurs and observed regularly by MCNV and District staff: "One day I heard some of them shouting enthusiastically 'It's time for lunch', I'm going to school to have lunch'." (R13, micro-entrepreneur).

Children's food preferences and hygiene practices - Children's food preferences were influenced, but also their eating regime became more regular under teachers' supervision, and children were motivated by eating with their peers at school, as confirmed by MCNV and District staff observations during regular visits to schools and talking with parents and teachers. A micro-entrepreneur explained: "When children are at home, they do not eat much. Parents do not encourage them. At school, they are together with their friends, so they eat more."(R14, micro-entrepreneur). Increased school attendance also had a 
significant impact on children's hygiene practices, especially hand washing, beyond the school routine, as reported in the Commune FGD: "Also at home, children have become proactive in washing their hands before eating and after the toilet." (G2, Commune FGD).

Nutritional status - Respondents from different stakeholder groups concurred that the nutritious school meals together with improved feeding and hygiene greatly contributed to better dietary intake and nutritional status of the nursery school children. A reduction in children's undernutrition was reported by several sources; a District official commented: "Since March 2018, we implement the school meal program and we have observed that the malnutrition status clearly reduced." (R2, District education). From a micro-entrepreneur: "Previously, the children looked thinner and shorter but now they look much much better. It is clear that a regular eating regime helps." (R13, micro-entrepreneur). Many parents also acknowledged the better nutritional status of their children and associated it with their improved school diet, as one described: "The child gains more weight when she joins the school meal, I think because they have good food intake and drink milk. In the past, she was 11 kg; since she joined school meals, I weighed her at 13 kg." (R10, Parent). The reported improvements were validated by the results of the official quarterly growth monitoring, as well as the observation by MCNV and district staff. The safety of school meals was also mentioned: "I think school meals provide clean food with sufficient nutrition for malnourished children. It helps improve children's health. We are very happy about that." (R12, Parent).

\section{Observed changes: parents}

Seeing the results of the intervention, in terms of children's improved nutritional status, was crucial in motivating parents to change; not only did they change their caring, feeding and hygienic practices, they also became more willing to support the school feeding program and the micro-entrepreneurs.

Caring and feeding practices - Children were important agents of change in the household. Their explicit request to eat food similar to school meals at home was instrumental to changes in parents' practices. District officials reported: "When children came home, they told their parents about the good food at school. Parents started to be concerned about food intake, because through the school meal they recognize that their children really like the new food, so they try to learn to make the same new dishes at home."(R2, District education). Similarly, a teacher explained: "Now parents can cook soup or other meals learned from the school, instead of feeding their children with cassava leaves like before." (R27, Teacher). This point was confirmed by a micro-entrepreneur: "One day, Ms Hien came to my shop, gave me compliments for the food I cooked, and asked me to show her the recipe and the whole process." (R7, micro-entrepreneur). The changes in parents' caring and feeding practices were also the result of the synergy between the HGSF component and the nutrition education activities of the NSA program. The monthly household group meetings increased parents' awareness of the causes and impacts of malnutrition and the behaviour changes needed to address the problem, as described by a father: "Many mothers are concerned with the nutritional status of their children, they do not want their children to get malnutrition. Now, they know how to take care of their children and how to cook for them."(R12, Parent). For example, parents understood the need for children to eat a nutritious breakfast, as noted in the District and Commune FGDs: "Before, parents fed breakfast to their child with anything, not necessarily nutritious food. For example, instant noodles, or even no breakfast, but now the parents care about nutritious breakfasts like nutritious porridge." (G2, Commune FGD). Mothers improved their cooking skills also thanks to demonstrations during group meetings, which encouraged the use of locally produced nutritious foods, reinforcing the synergy among NSA program components. The self-reported improvement in cooking practices was confirmed by MCNV staff observations. Improvements in WASH-related practices and the hygiene of the household environment were also reported: "I recognize that parents are proactive in personal hygiene for their children even when the children are not ill. They help their children brush their teeth, wash faces and hands in the mornings and put on clean clothes. They also clean their house, clean animal cages and fence the garden to avoid disease transmission." (G2, Commune FGD). Altogether, the change in parents' caring and feeding behaviour was considered remarkable. A teacher explained the difference before and after the intervention: "Children are taken care of in a better way compared to the past. I almost cried when I first started teaching at the nursery school in 2013. At that time, most parents and elderly people did pay much attention to sanitation and to their children." (R18, Teacher).

Willingness to pay - Overall, parents expressed an increased interest in the nutritional status of their children and, related to that, a higher commitment to pay for the school meals, confirmed by MCNV and District staff observations. From January 2020, parents contribute $50 \%$ of the school meal cost. For most parents, the willingness to pay matched their capacity to pay, as exemplified by a mother: "If the school asks us to pay for the school meals, then we will pay. We can afford 15,000 VND per day." (R9, VHW/parent). Several respondents also noticed a slight but relevant change in spending habits, with parents prioritizing the school meal over other expenditures. A micro-entrepreneur illustrated this point: "Parents tend to rely on the state's support, and fathers often spend money buying beer and so. But recently, there has been a minor change; they pay more interest to their children's schooling, for example by buying breakfast for their children." (R7, micro-entrepreneur). In view of 2021, which marks the end of the NSA program's subsidies, $80 \%$ of the parents expressed their willingness to continue paying for the school meals. As remarked by a micro-entrepreneur, if school meals are not provided anymore and children start losing weight, parents will feel a strong incentive to reinstate the school feeding: "Parents will make payment if their children lose weight. They (mothers) said if they can buy a crate of beer for 150,000 VND, they can pay for their children's meals." (R17, micro-entrepreneur). While the majority of the households could be willing and able to sustain the school feeding, it might not be true for the poor and most disadvantaged ones. The latter already struggled to pay the school meals when they were subsidized and may drop out once the program's financial support ends, as suggested by a parent: "Sometimes we discuss about the school meals among mothers. Those who support the school meals say that it is not much money and that we should continue to pay for them. For those who are poor, I think, it is easier to accept when the project supports 50\%. But when they have to pay 100\%, it is quite difficult." (R16, Parent).

\section{Observed changes: community}

Community-wide changes relevant for the sustainability of the HGSF interventions were also observed. They concerned the strengthening of the local system through a more stable supply and demand of home-grown nutritious foods, increased knowledge sharing, and building social capital.

HGSF and the local food system - The HGSF component contributed to increased demand locally for nutritional foods, strengthening the "home-grown" dimension. The synergy between these two components of the NSA program was self-reinforcing, as the increased demand incentivised the production system, enhancing local availability of and access to nutritious foods. Although the production surplus provided a modest contribution to the HGSF 
implementation, it showed good potential, as described by a micro-entrepreneur: "Rice is nearly 100\% locally supplied. Around $30 \%-40 \%$ of chickens are bought from local people. About $20 \%$ of eggs are locally supplied. $50 \%$ of vegetables are provided by locals and motorcycle vendors." (R7, micro-entrepreneur). A more self-reliant food system potentially decreased the dependence of micro-entrepreneurs on external sources, a convenient option especially when, due to heavy rainfall, blocked roads prevent mobile vendors from reaching the village and micro-entrepreneurs from going to the district market for supplies. Over the four years of the NSA program, the food system in Phu Mo progressively changed, from being heavily oriented towards cash crops and largely dependent on external sources for the procurement of nutrient-rich foods to a partially self-reliant nutrition-sensitive food system. District officials described this change: "In the past, villagers only focused on planting cassava or working as farm labour to earn money that they used to buy food. Now, many households are also concerned about raising chickens for eggs and planting vegetables to improve their daily intake, and for other households in the community. (....) Before, villagers bought almost $100 \%$ of their food from outside, but now, thanks to the agricultural models, they produce nutritious food in their village." (R3, District agriculture). These changes, especially in terms of diversification of production systems, were confirmed by the regular observations and transect walks made by MCNV and District staff. Community-wide, the increase in local production not only improved household food security and reduced food expenditures but also created an income opportunity when surplus was sold, which at least $15 \%$ of the households were doing. A district official described the changes in the food system: "Other households raise chicken and quails and plant vegetables for themselves, but they also sell to other members of the community and the local micro-enterprise, to create more nutritious food and to gain income for their family."(R3, District agriculture). These changes resulted partly from the synergy between the agricultural and the HGSF components of the NSA program.

Increased knowledge sharing - Meetings such as those organised in the context of the school feeding and the monthly household group gatherings provided an opportunity to strengthen relationships but also to encourage peer-to-peer learning. A VHW mentioned: "The monthly meetings make the mothers closer. The meetings are also a chance for exchange and learning, each mother knows a bit and they share this knowledge."(R9, VHW/parent). Another knowledgesharing event, the Childhood Nutrition Competition, was emphasised by a teacher: "Both parents and teachers are keen on this event. Last year, when my class took part in the competition, parents were so enthusiastic and interested to exchange information." (R8, Teacher). The participatory knowledge-sharing events were useful in increasing awareness and support for school feeding, but also promoted the benefits of the HGSF intervention. Knowledge sharing was also encouraged between the local government and the communities, building trust and providing an opportunity to improve the design of the intervention without fear of failure. A commune representative explained: "The schools collaborate with the health and agriculture sectors and the local enterprise. Every month we meet to agree on the provision of school meals and monitor the quality and food safety of the meals. We also join the household meetings together with agriculture or health staff." (R4, Commune nursery school principal).

Social capital - The HGSF intervention increased the collaboration between parents and teachers, and others. Several sources recognised that the regular meetings held with the teachers, parents and micro-entrepreneurs increased social capital, enhancing support for school feeding. Better communication, bonds and trust among community members and the development of an informal community of practice engaging with NSA contributed to address the undernutrition challenge as a community and not just as individuals. A District official described how social capital developed: "One positive impact I see is the collaboration and relationships among the community. For example, when the children come home, they praise the food at school, which makes parents believe in the teachers and local microenterprise."(R2, District education). The synergy between the HGSF component and the nutrition education activities of the NSA program further contributed to the improvement in social capital, creating benefits beyond the school environment. In fact, during the household group meetings, parents of children not attending nursery schools learned about the benefits of school feeding. As the micro-entrepreneurs prepared meals for schools but also sold them at their shop, children too young to attend the nursery school could also benefit, as observed by MCNV staff and described by a District official: "I think through the school meals, communication in the community increased. For example, some parents have children who don't go to school, but they hear from parents who have children at school, which stimulates them to buy food for their children from the local enterprises. And this also brings change to their homes." (R2, District education). According to MCNV staff, increased social capital was also observed in the closer relations between communities and District, as evidenced by villagers calling the district agricultural staff directly with technical questions or where and how to buy materials.

\section{Facilitators}

Several factors facilitated the positive changes observed among children, parents and the community in relation to the HGSF intervention. The identified facilitators - role models and enhanced confidence, change agents including committed micro-entrepreneurs - all contributed to increase the beneficiaries' motivation to change.

Role models and enhanced confidence - Individuals who successfully benefitted from the intervention, whose children's nutritional status was visibly improved, acted as role models by sharing their success story with others during household group meetings or at schools. A commune representative reported: "At school, when a child looks healthy and well-developed, teachers will be asked about the parents of that child, because other parents would like to meet them." (R4, Commune nursery school principal). Exposure to positive examples and the tangible benefits of the intervention gave confidence to other beneficiaries and motivated them to replicate good practices. Using their context knowledge, the NSA program implementers effectively integrated this mechanism into the implementation strategy, as a District official recounted: "We select a household or model with good capacity. For ethnic minority people it should be quite easy; when they see someone in the community who has success, they are eager to learn. So we focus on positive examples for others to learn and change their behaviour." (R1, District health). The gained sense of empowerment and increased self-confidence were reported by several stakeholders, including the Phu Mo school principal: "Because we successfully implemented the NSA program in Phu Mo, we should bring people from other communes to visit the school meal model and the agriculture nutrition model here." (R4, Commune nursery school principal). MCNV staff observed that even the pride and confidence of the district government increased when they could scale-up the school meal model (from 5 to 15 nursery schools by September 2020 ) and its success was recognised in the national media.

Change agents - The individuals in each community who actively promoted change were of three types. The first group comprised local people who could influence the parents. The active engagement of socially recognised individuals capable of influencing others was deemed effective and culturally

Page $12 / 23$ 
appropriate, and was planned at the onset to leverage community buy-in for the HGSF intervention. The Phu Mo school principal explained: "In order to convince the parents, besides the education sector, we also use the voices of different stakeholders, for example the women's representative, the village heads and the elderly of the community. So in the meeting with the parents we invite these people, they come together to convince the parents." (R4, Commune nursery school principal). Secondly, as previously mentioned, nursery school children also acted as change agents within their own families. By appreciating the meals prepared by the micro-entrepreneurs and requesting their parents to cook similar dishes, they triggered changes in home-cooking practices. The third type is the micro-entrepreneurs, described in detail in the next paragraph.

Committed micro-entrepreneurs - Selecting committed and ambitious local candidates with the most promising capacity to set up successful food microenterprises was part of the implementation strategy. Social entrepreneurship proved to be a crucial facilitator of several aspects of the program, beyond the HGSF component. In fact, micro-entrepreneurs supplied nutritious meals not only to nursery schools but also to others in the community, thus benefitting more children while expanding their income opportunities and increasing demand for home-grown nutritious foods. A VHW explained the extended benefits of the micro-entrepreneurs' role: "Mothers of children not yet attending preschool buy porridge for breakfast, for both well-and undernourished children, bringing them nutritional food." (R9, VHW/parent). Furthermore, micro-entrepreneurs facilitated changes in home cooking practices by demonstrating their recipes to others. Their main motivation was not money, but the commitment to their own communities and their ability to contribute to reducing undernutrition, as observed by MCNV and District staff and explained by one micro-entrepreneur: "I like it (school feeding program) very much. It's not because we can earn a bit more money, but the most important thing is that we find joy in what we are doing, and we are happy when we see the kids look better and playful." (R13, micro-entrepreneur). That their motivation was not money was confirmed by their actions, as most micro-entrepreneurs continued to serve meals to all children, even those who were unable to pay on time. A micro-entrepreneur stated: "If just $50 \%$ of parents pay for the school meal, we will continue to serve their children. We just think that it is a pity for the rest of them not to enjoy school meals while their peers do. For us, it is most important to find out how to help all children in this community to have access to nutritious school meals." (R13, micro-entrepreneur). Micro-entrepreneurs' commitment and ambition were reflected in their quest to improve the menus to fit better the needs and preferences of the children, parents and teachers, but also their openness to feedback, as explained by a micro-entrepreneur: "I got complaints from parents and school children about the quality of the food. Then I drew lessons and tried to improve the portions. My expectation is to serve good food, and I feel happy when they are satisfied with it. The parents pay weekly visits to supervise whether the food is hygienic. I am quite happy because the food now is good enough." (R7, micro-entrepreneur).

\section{Barriers}

While stakeholders valued the contribution of the HGSF intervention in addressing the undernutrition problem, they also acknowledged the existence of several poverty-related barriers to participation, namely the need for more economically disadvantaged households to seek paid labour outside the communities, their inability to pay for school meals on time, and limited financial management capacity.

Struggling for money and lacking time - The limited financial capacity of the poor and more vulnerable households (about $44 \%$ of Phu Mo households in 2019) was recognised as a critical barrier for their participation in the HGSF; observation by MCNV staff confirmed this as a problem. The barrier persisted in spite of the NSA program subsidies and the willingness of these households to contribute. Poor households often relied on waged labour that kept them away from home, often for extended periods. Due to pressing priorities and their absence from home, those households lacked time to care for their children and to participate in relevant program activities, such as voluntary feeding shifts at nursery schools, school and household group meetings, and home gardens. A Commune representative reported: "There is a lot of poverty in this area, so the people focus on working in the field or as hired labour. That creates difficulties in taking care of their children and feeding them." (R6, Commune health).

Late payments - Since the most disadvantaged households relied almost entirely on agricultural revenues, their income fluctuated, with droughts and floods affecting both production and income. They often failed to pay for school meals on time, thus affecting program implementation: "In the community there are many households in a difficult economic situation, so sometimes they contribute money late, this also influences the project." (R2, District education). This point was validated by MCNV and District staff observations. A teacher clarified that poor households are not unwilling to pay but often lack the finances to pay on time: "There is no question that parents love the school meal model, but they have trouble earning enough money to make payments. The period from September to December is the rainy season, when parents cannot earn enough money for daily living." (R8, Teacher).

Poor financial management - Several stakeholders confirmed that for poor households, it is challenging to manage money on a monthly or even yearly basis, such as subsidies for school meals and supplies received from the Government twice yearly. A micro-entrepreneur explained: "They are used to spending on a daily basis, spending whenever they have money, they are not used to saving for a month to pay for the school meals. Looking at the money to be paid for the school meals in a month, it seems too much for them. They could manage it if they pay around VND 10,000 to 15,000 per day, they might think that is affordable." (R13, micro-entrepreneurs).

\section{Sustainability challenges and strategies}

With the end of the NSA program in sight, respondents identified critical challenges for the sustainability of the HGSF intervention and outlined potential strategies to sustain it. Customisation of payment methods to facilitate the participation of the most disadvantaged households, becoming semi-boarding schools, and strengthening the social entrepreneurship component were among the options proposed.

\section{Challenges}

School meals funding - In the framework of the NSA program, the school meals were subsidised at a progressively decreasing rate; from 2021 their cost would be entirely covered by the parents. However, during implementation, it became evident that the poorest households struggled to remain engaged in school feeding, even with program support and their bi-annual Government subsidy. According to most respondents, once external support ends, the majority 
of the households would probably be willing and able to continue paying for school feeding. However, vulnerable households, whose children would benefit most from the nutritious school meals, would probably drop out.

Limited resilience to shocks - Despite their remote location, Phu Mo communities were not exempted from the impact of the COVID-19 pandemic. For three months (February-April 2020) all program activities were suspended, schools and shops were closed, and children stayed home. The negative impact was immediately visible. By the end of the quarantine, the proportion of underweight children was almost as high as at the beginning of the school year. As a teacher recounted: "Some students were only $9 \mathrm{~kg}$ when they enrolled in my class but after the first semester, they were $11 \mathrm{~kg}$. When the pandemic restrictions ended, children had lost weight and went back to their original weight. Now, children have to come back to school to start gaining weight again." (R18, Teacher). District staff reported observing this situation during field visits following the quarantine. The COVID-19 pandemic was a serious setback for these poor communities. Nevertheless, it encourages reflection on the importance of developing an even more self-reliant food system able to safeguard local food security and nutrition. It also confirms the relevance of addressing undernutrition through multiple entry points (community, household and nursery school). However, doubts were raised about the households' capacity to continue applying the improved caring, feeding and agricultural practices when challenges arise. Seeing the children lose weight could have indirectly contributed to increasing parents' trust and support for the HGSF, potentially increasing its sustainability, as described by a VHW/parent: "I know this project helps improve children's nutritional status. During the last three months of the epidemic, the children did not have sufficient nutritious food intake. Now the nursery schools open again. When I was there I saw the children eat eagerly. So, when the project finishes, I will continue to pay for the school meals for my children." (R9, VHW/parent). The local authorities also expressed renewed support for the school feeding: "When the COVID crisis is over and the school is open again, the school meals will immediately start. I see no problem." (R2, District education).

\section{Strategies}

Financial sustainability of school feeding - Micro-entrepreneurs, teachers and parents envisaged a number of strategies to address the barriers for the poorest households and sustain school feeding after the NSA program ends. Tailor-made payments (including alignment of the school meal payment with the disbursement of the Government subsidy) and fundraising were among the solutions discussed in the District FGD: "First we will continue to convince the parents to maintain the school meal; second we will discuss with the local micro-enterprise on alternative payments, for example when the local microenterprise hires labour to harvest cassava or rice, they can hire these households. Or the micro-enterprise can wait until these families harvest their crops or earn money, then they can pay. (...) We can mobilize funding from charity groups in Phu Yen." (G1, District FGD). Furthermore, a micro-entrepreneur explained in more detail her arrangement with the parents and the teachers: "In the last rainy season, some parents had no work and lacked cash to pay for school meals. So I talked to the teachers and told them to collect as much as possible, then give me the list of parents who still owed money; they can pay me later, when they have money." (R13, micro-entrepreneur). The effectiveness of such customised payment arrangements has also been observed by MCNV staff.

Semi-boarding school - Many parents expressed a preference for a semi-boarding arrangement and extension to younger children. Children could take a nap at school after lunch, giving parents more time to work and raise income to pay for the semi-boarding arrangement. By September 2020, in fact, four of the nursery schools were providing this service for 113 children, as a follow-up to the school meal program.

Social support networks - Another strategy suggested to support the more disadvantaged households relying on waged labour outside the communities was to mobilize social support networks. Those parents could ask other community members to look after their children. This way children could still be adequately fed and have growth monitoring and healthcare like children from better-off households. This proposal not only showed stronger solidarity and use of social capital but also parents' greater awareness of appropriate care and feeding practices, as remarked in the Commune FGD: "There is a new behaviour of caring for the children; in the past, parents just went for work, but now if they work they try to find someone to help take care of their children." (G2, Commune FGD).

Social entrepreneurship - Respondents recommended investing more in the micro-enterprises because they meet community needs, are embedded in and committed to their communities, and are perceived to be sustainable. District Agriculture staff observed that there had never been such local enterprises in the villages and most food was brought by mobile vendors, but now, the role of the microentrepreneurs is recognised, as exemplified by their growing number, and should be supported. A District health representative also emphasised the importance of good collaboration between public and private sectors: "I think that the collaboration between private sector and local government within the NSA project is very good, but the local private sector plays the most important role because they live in the community. (....) I know from other projects, people from outside come to work and afterwards they go out and there are no results. So, for me, the investment in the locality is very important. "(R1, District health).

Reduced reliance on program support - From 2017 to 2020, MCNV provided financial and technical support to the NSA program and coordinated the multilevel/multi-stakeholder partnership. The potential risk that, at the end of the program MCNV would leave a void difficult to fill, led several respondents to reflect on the program exit strategy and the way forward. They suggested that the district government should take over the coordinating and supporting role to sustain the collaboration and replicate the successful experience of Phu Mo in other communes. Respondents advised integrating the NSA approach into prospective government programs for the social and economic development of upland communities, and developing training materials to continue building the knowledge and capacity on NSA of all sectors involved.

\section{Discussion}

The results of our study show that a HGSF intervention in nursery schools, providing nutritious and diverse meals using partly home-grown products, could improve children's nutritional status, school attendance, food preferences and WASH practices at home. We found a perceived improvement in parents' caring and feeding practices and an increased commitment to HGSF; many parents expressed willingness to cover the full cost of school meals. Positive changes were also observed at community level. Key stakeholders reported that, compared to the NSA program baseline situation, the local food system became less

Page $14 / 23$ 
cash crop-oriented and more self-reliant in production of nutrient-rich foods, contributing to enhanced food security and livelihood when surplus was sold, some of it to the microentrepreneurs providing the school meals. An increase in social capital was also observed, with better communication, bonds and trust among community members.

These positive changes were attributed not just to HGSF on its own, but to the synergy among the NSA program components. Crucial facilitators were enhanced confidence and motivation, especially among parents, thanks to positive influences of role models and change agents such as the microentrepreneurs. The most important barrier was poverty, which, along with the limited resilience to external shocks, poses serious challenges to sustainability. Custom-made payments for disadvantaged households, mobilisation of social support networks, and increased investment in social entrepreneurship could be viable strategies to sustain HGSF, particularly in isolated areas.

\section{HGSF synergy with agriculture component}

The results of our study suggest that in remote and underserved areas having less developed, cash-crop oriented food systems, HGSF can show many benefits, when integrated in a broader NSA program that mobilises the entire community and stimulates both supply and demand of nutritious food. In line with the theory of change underpinning $\operatorname{HGSF}[32,48,49]$, this pilot intervention showed that HGSF contributed to transformation. Before the NSA program, Phu Mo commune produced mostly cassava and relied significantly on external food supplies; none of the nursery schools provided school meals. The declining returns from cassava production, identified at baseline, may have triggered a change, creating a window of opportunity for NSA interventions. Similar to other studies promoting direct supply linkages with local farmers [30,33], the NSA program contributed to the creation of a short supply chain through development of context-appropriate agricultural models and establishment of social micro-enterprises as key intermediaries for procurement and catering. To overcome initial supply constraints, program interventions boosted local farmers' capacity (training, material inputs, technical assistance) as envisaged in previous studies $[27,49]$. The design choice to implement the agricultural component prior to HGSF was instrumental, as the surplus production could partly fulfil the need for school meal ingredients. According to Olney et al. [50], the impact of agriculture interventions on production and consumption can only be observed after sufficient time. The benefits of carefully sequencing the activities in NSA programs were highlighted by Nordhagen et al. [51]; staggering of supply and demand sides was also suggested for data collection during monitoring [41]. While stimulation of the supply side was necessary, selling surplus food to the micro-enterprises and to other households occurred spontaneously, resulting from community dynamics rather than program incentives. In our study, only in the second year of implementation did the self-reinforcing cycle of supply and demand for local foods generate visible benefits.

\section{Food sources and influencing factors}

On average, about $44 \%$ of the foods used for the school meals in Phu Mo were home-grown. That the average reached this high level was predominantly because of the procurement choices of two micro-entrepreneurs catering for Phu Tien and the adjacent villages of Phu Giang and Phu Loi. The difference in home-grown procurement was largely explained by the availability of the promoted nutritious foods in those villages. These were the first villages to implement the NSA models, and their production capacity progressively increased from 2018, creating a surplus sufficient to address part of the HGSF demand. In Phu Hai and Phu Dong, the agricultural component started later, thus, at the time of this study, their food availability was lower. While Phu Hai showed promising results in terms of productivity and diversification, Phu Dong's production potential was undermined by a lack of water and space for home gardens. The limited local availability of recommended foods, such as vegetables and eggs, as a constraint to full-fledged implementation of NSA interventions has been reported. Schreinemachers et al. [52], investigating the impact of school gardens and nutrition education in Burkina Faso, observed that although children were taught the importance of vegetables for their health, vegetables were hardly included in school menus or home diets, because of limited availability.

As noted above, seasonality could affect HGSF by influencing food supply (availability and diversity) and prices [15, 28, 30, 33], thereby determining the choice of food sources for the school meals. In Phu Mo, seasonal changes in rainfall might have justified differences in the menus. However, we found little difference in school meal diversity and cost between seasons. It could be that, during summer, when local production decreases but road access improves, micro-entrepreneurs may use more external sources to procure foods at convenient prices. This explanation aligns with FAO \& WFP [15] recommendations on temporary substitutions to fill seasonal gaps in food supply to ensure a smooth continuation of HGSF. Storage, food processing and preservation could offer other viable options [15]; these were not investigated here, considering the limited local production surplus, but may become interesting options in the future.

Seasonal factors are foreseeable and can be accounted for, but natural disasters and external shocks are less predictable and could undermine the limited resilience of local food systems, with direct consequences on HGSF. In our case, COVID-19 posed a serious threat to the people's health and the local food system. In view of future shocks and to prevent disruptions in supply, strategies such as diversification of agricultural production, including biofortified crops, need to be further prioritised [53]. From the demand-side, HGSF could offer alternatives to ensure continued meals for students even during the COVID pandemic, as recommended for the Brazil National School Feeding Program [54]. Strategies include mobilising emergency funds and incentives for local food purchases, but also providing takeout lunches and/or food kits, particularly for disadvantaged families.

\section{School meal diversity}

We found that the composition of the school meals increased daily dietary diversity for the children from 1-2 food groups at baseline to 3-4 after intervention. In Phu Mo, the children had breakfast and lunch at school and the quality of the food consumed at home was reported to have improved under the influence of the NSA program. Our findings align with a study assessing dietary diversity of children 3-5 years old in a school nutrition pilot program in poor, ethnic minority communities in rural China [45]. The same study also remarked that since children consumed most of their food at school (breakfast and lunch), the nursery school meals played a critical role in children's dietary diversity [45]. 
The improvements in food diversity for the children were similar to those reported from HGSF programs in Nepal [30]. One noted difference was the almost total absence of animal proteins in the school children's diet in the Nepal program, whereas the inclusion of 'meat and fish' in school menus was very prominent in our study. The same difference was observed comparing our results to those of the Ghana School Feeding Program, which since 2005 has progressively embraced the HGSF concept [33]. The inclusion of meat and fish in the meals served in Phu Mo nursery schools aligned with the animal protein requirements of 4-6 year-old children in the Recommended Dietary Allowances for Vietnam [55]. The limited presence of animal food sources observed in other studies could be explained by factors such as culture-related diet preferences, a focus on increasing micronutrient content using less expensive foods (legumes and green leafy vegetables), or local availability and affordability of animal food sources [28]. Finally, milk was added to Phu Mo schools menus through a provincial program launched in 2019 , showing the potential for public-private co-located interventions aimed at improving dietary diversity among pre-school children.

\section{Improved nutritional status and school attendance}

The main aim of the HGSF in Phu Mo commune was to reduce undernutrition among the young children. Stakeholders from all sectors as well as parents reported consistently that the children had gained weight and were better nourished after a few months of participating in the HGSF program. The anthropometric data provided a positive, though indicative, effect on rates of underweight. Conversely, a review of studies conducted on the Ghana School Feeding Programme over 2010-2019 showed that while the program had been generally effective in improving micronutrient and energy intakes, the results on children's nutritional status were mixed and less conclusive [23].

In our study, particularly noticeable was the quick reduction in underweight in the first quarter of 2019-2020 (before COVID-19 quarantine) which could be partly attributed to cumulative learning since the start of implementation; teachers, parents/farmers and micro-entrepreneurs were more experienced in implementing HGSF, and children could have become familiar with the meals and better feeding and hygiene practices at school or at the household group meetings. In line with previous findings $[30,56]$, our study confirms the importance of sustained nutrition education among parents, caterers and school staff on the need to consume diverse and nutritious meals to have better-nourished children. It also emphasises the relevance of multiple entry points (community, school and household) to improve children's nutrition, health and well-being and the need for a closer involvement of parents/caretakers and other community members in school-based programs. Similar conclusions, though from a health perspective, were drawn in a study investigating an NSA school-based project in Burkina Faso [25].

We found that school meals were instrumental in increasing children's presence at school. Children were reported to be accompanied to school more frequently and on time for breakfast. School attendance had a positive effect on children's meal frequency, food preferences and hygiene practices. These factors combined with the beneficial effect of diverse and nutritious school meals, contributed to improved children's nutritional status as suggested by both qualitative and quantitative data. A mixed methods study on HGSF in Nepal reported similar outcomes in terms of increased school attendance, improved dietary intake and hygiene practices [30]. Furthermore, the study by Tette \& Enos [23] reported consistent findings of increased school enrolment with partial increases in attendance, punctuality and retention.

\section{Cost of school meals}

Despite its benefits, HGSF implementation depends significantly on affordability [30], particularly by households in more disadvantaged socioeconomic conditions. In Phu Mo HGSF pilot, the school meal costs were about USD 0.65/child/day, or USD 13 per month. For the community, this would be a sound investment, as recent estimates from a cost-benefit analysis in Lao PDR show that for every dollar spent in school meal programs, the economic return is between USD 5 and USD 6.1 over the lifetime of a beneficiary [57]. However, as government subsidies cover only $45 \%$ of the school meal costs for the poorest households, HGSF self-sustenance in Phu Mo from January 2021 raises concerns because key sustainability strategies envisioned by the local stakeholders, such as customised payments, rely heavily on the social support, flexibility and financial capacity of the micro-entrepreneurs.

\section{Micro-entrepreneurs' motivation and sustainability prospects}

As stated, HGSF sustainability depends significantly on the incentives for the local micro-enterprises to maintain and scale up activities. In the current cost structure, micro-entrepreneurs received a standard daily amount for their labour (USD 4.30) which was lower than the average daily wage for farm labour (USD 6.5). The micro-entrepreneurs did not make a profit on the school meals; their personal motivation and commitment to their communities played a greater role than financial incentives. The female micro-entrepreneurs perceived practical benefits from running their business: more regular work compared to hired labour, being located in their own villages (close to the schools and their homes), the possibility to combine work and household chores but also to mobilise family members for meal preparation and delivery when needed. The micro-entrepreneurs showed pride in their role and its social recognition as well as their contribution to address the undernutrition challenge in their communities. Respect, trust, social recognition and appreciation for the work done were common denominators in other studies that noted the motivational factor among local human resources at the frontline of NSA projects [58-60]. While a lack of profit could be acceptable in the framework of a program, given the support provided, there are some concerns about sustainability, as micro-entrepreneurs would not have enough money to replace or keep equipment and premises up to standards. Long-term sustainability may be achieved by broadening the range of activities beyond school meal catering. Also, as diversification and appreciation for their services increase, more micro-enterprises could be established thus decreasing the responsibility of and reliance on the few existing ones, creating opportunities for others and enhancing HGSF sustainability. The latest report from September 2020 informs us that there were then seven micro-enterprises in Dong Xuan, serving 12 nursery schools, providing meals for 340 children; another 85 children received meals from kitchens established in three more nursery schools. This represents a significant change from $2017-2018$, when only one of the 16 nursery schools in the District provided meals. Clearly the school meals programme has been accepted and supported by the communities and the increased availability of home-grown nutritious foods facilitates that process.

\section{Change agents and role models as key facilitators in the process}


As noted above, for changes to occur, certain community actors can be more influential than others. Change agents and role models are common features in Vietnamese culture. The NSA program leveraged on these contextual features and effectively integrated them in the implementation strategy to stimulate positive changes. Our study shows how socially recognised authorities, such as village leaders and women's representatives, but also others such as microentrepreneurs and school children, could act as facilitators in the change process. The importance of key influencers and change agents as part of the community mobilisation and engagement strategy has been highlighted in other NSA studies [61-63]. For example, Ogoye-Ndegwa et al. [62] described ways to empower primary school children to become change agents for community development in the context of a school-based nutrition action-research project in Kenya. In our study, nursery school children triggered changes in the home environment, a spin-off not envisaged in the ex-ante program theory. However, we concur with Erismann et al. [25] that although children can be effective at promoting messages received at school, the uptake and translation of these messages into actual behaviour changes at home may be difficult and take time. Simultaneous actions at community, school and household level could have accelerated the change process in Phu Mo, for example by reinforcing messages through a multi-pronged communication strategy as reported in the process evaluation of other NSA projects $[43,64]$.

\section{Limitations}

Due to logistic and financial constraints, it was not possible to assess school children's dietary diversity using a 24-hour recall for this review; school meal menus were used as a proxy for the food intake. Anthropometric data are collected three times a year according to the Ministry of Education and Training protocol. However, except for 2019-2020, no measurements were taken in May before children went on summer holiday, thus failing to capture the school meals' full impact. Some study limitations could be intrinsic to horizontal content analyses. To ensure coding fidelity and avoid overemphasis of quotes, transcripts were firstly coded by one researcher, with subsequent reviews of raw data and codes by the other researchers. Both SSIs and FGDs were used to minimise social response bias. The same trained local staff and translators were involved throughout the study to prevent translation bias and ensure cultural appropriateness of tools and quality of transcripts.

\section{Conclusions}

Our mixed methods review expands the knowledge base on HGSF by describing successful implementation of a HGSF pilot in a remote, poor ethnic minority community with a high prevalence of undernutrition among preschool children, integrated in a multi-sectoral program that mobilises the entire community and stimulates both supply and demand of nutritious food. HGSF in synergy with the other program components generated a range of benefits directly for the children. The positive effects spilled over to the home environment and the community. The local food system became more self-reliant for the production of nutritious foods, contributing to HGSF but also to better livelihood and household food security. This experience confirmed the importance of tailoring interventions to the context in which they are implemented and the power of integrating context factors, particularly culture-related ones, in the program implementation strategy, to stimulate positive changes that can be more easily accepted, adopted and sustained by local communities. Looking forward to the upscaling of HGSF, in a scenario of declining external funds and increasing community-ownership, it will be important to continue investing in social microenterprises and to ensure that local budgetary economies are not made at the expense of good quality meals and the educational experience that is crucial for children in these formative years.

\section{Abbreviations}

\section{CU5}

Children under five years of age; FAO:Food and Agriculture Organization; FGD:Focus group discussion; HGSF:Home-grown school feeding; LMICs:Low- and middle- income countries; MCNV:Medical Committee Netherlands-Vietnam; NSA:Nutrition-sensitive agriculture; SSI:Semi-structured interview; USD:United States dollar; VHW:Village health workers; VND:Vietnamese Dong; WASH:Water, sanitation and hygiene; WAZ:Weight-for-age-Z-score; WFP:World Food Programme; WHO:World Health Organization.

\section{Declarations}

\section{Ethics approval and consent to participate}

The study was approved by the Institutional Ethics Committee of Hue University of Medicine and Pharmacy in Vietnam (registration number H2018/010). All procedures performed in studies involving human participants were in accordance with the ethical standards of the institutional and/or national research committee and with the 1964 Helsinki Declaration and its later amendments or comparable ethical standards. Written informed consent was obtained from all individual participants included in the study (see overview of respondents in Table 1). No interviews were done with children.

\section{Consent for publication}

Not applicable

\section{Availability of data and material}

All data generated or analysed during this study are included in this published article. The complete data set is in Vietnamese but all transcribed material can be made available by the corresponding author on request.

\section{Competing interests}

The authors declare that they have no competing interests. 


\section{Funding}

This study is part of the joint first authors' PhD research funded by the Netherlands Organisation for Scientific Research (NWO) - Food and Business Global Challenges Programme (grant number: W80.25.302). The funding agency did not play any role in the research design, execution of the study and the compilation of the article.

\section{Authors' contributions}

SDP and DND contributed equally to this work and qualify as first authors for this publication. About the specific contributions: all authors contributed to the study conception and design based on SDP initial ideas; data collection tools were jointly designed by SDP, DND, DDR and DE; data collection was undertaken by DND and DDR; coding and initial analysis were performed by DDR and all authors contributed to further analysis. The first draft of the manuscript was written by SDP and EPW, and all authors critically reviewed the following versions. All authors have read and approved of the final version of the paper and its submission.

\section{Acknowledgements}

The authors would like to thank all the stakeholders - informants and program implementers - that contributed to this study. Our sincere gratitude and appreciation goes to the people of Phu Mo commune (parents, children, farmers, micro-entrepreneurs, village health workers, health station and agriculture extension staff, nursery school teachers and principal, village authorities and the communities). We would also like to acknowledge the important contribution of Dong Xuan district staff from agriculture, health and education departments and Phu Yen provincial authorities. Special thanks goes to the Medical Committee Netherlands-Vietnam and the academic partners involved in the NSA program, specifically Hue University of Agriculture and Forestry and Hue University of Medicine and Pharmacy. Finally, we would like to thank the Netherlands Organisation for Scientific Research (NWO) - Food and Business Global Challenges Programme for the financial contribution to the NSA program.

\section{Authors' information}

SDP: PhD student at the Athena Institute of Vrije Universiteit Amsterdam (VU) and Sustainable Land Management specialist at the VU Centre for International Cooperation. DND: PhD student at the Athena Institute of Vrije Universiteit Amsterdam and chief of office at MCNV Central Vietnam. EPW: Guelph International Health Consulting, Amsterdam, The Netherlands. DE: Assistant professor of global health at the Athena Institute, Faculty of Science, Vrije Universiteit Amsterdam. JEWB: Professor of innovation and communication in health and life sciences and Director of the Athena Institute Faculty of Science, Vrije Universiteit Amsterdam.

\section{References}

1. FAO/IFAD/UNICEF/WFP/WHO. The State of Food Security and Nutrition in the World 2019. Safeguarding against economic slowdowns and downturns. Rome; 2019. Available from: https://www.unicef.org/media/55921/file/SOFI-2019-full-report.pdf

2. Development initiatives. 2018 Global Nutrition Report: Shining a light to spur action on nutrition. Global Nutrition Report. Bristol, UK; 2018. Available from: https://globalnutritionreport.org/reports/global-nutrition-report-2018/

3. UNICEF/WHO/WB Group. Levels and trends in child malnutrition: key findings of the 2019 Edition of the Joint Child Malnutrition Estimates. Geneva: WHO; 2019. Available from: https://reliefweb.int/sites/reliefweb.int/files/resources/Joint-malnutrition-estimates-April-2019.pdf.

4. Black RE, Allen LH, Bhutta ZA, Caulfield LE, de Onis M, Ezzati M, et al. Maternal and child undernutrition: global and regional exposures and health consequences. Lancet. 2008;371(9608):243-60.

5. Black RE, Victora CG, Walker SP, Bhutta ZA, Christian P, De Onis M, et al. Maternal and child undernutrition and overweight in low-income and middleincome countries. Lancet. 2013;382(9890):427-51.

6. Reinhardt K, Fanzo J. Addressing Chronic Malnutrition through Multi-Sectoral, Sustainable Approaches: A Review of the Causes and Consequences. Front Nutr. 2014;1(August):1-11.

7. Grantham-McGregor S, Cheung YB, Cueto S, Glewwe P, Richter L, Strupp B. Developmental potential in the first 5 years for children in developing countries. Lancet. 2007;369(9555):60-70.

8. Hoddinott J, Behrman JR, Maluccio JA, Melgar P, Quisumbing AR, Ramirez-Zea M, et al. Adult consequences of growth failure in early childhood. Am J Clin Nutr. 2013;98(5):1170-8.

9. Stewart CP, lannotti L, Dewey KG, Michaelsen KF, Onyango AW. Contextualising complementary feeding in a broader framework for stunting prevention. Matern Child Nutr. 2013;9(S2):27-45.

10. Victora CG, Adair L, Fall C, Hallal PC, Martorell R, Richter L, et al. Maternal and child undernutrition: consequences for adult health and human capital. Lancet. 2008;371(9609):340-57.

11. Bhutta ZA, Das JK, Rizvi A, Gaffey MF, Walker N, Horton S, et al. Evidence-based interventions for improvement of maternal and child nutrition: What can be done and at what cost? Lancet. 2013;382(9890):452-77.

12. Ruel MT, Alderman $\mathrm{H}$. Nutrition-sensitive interventions and programmes: How can they help to accelerate progress in improving maternal and child nutrition? Lancet. 2013;382(9891):536-51.

13. World Bank. Improving nutrition through multisectoral approaches. Washington, DC: World Bank; 2013. Available from: http://documents.worldbank.org/curated/en/625661468329649726/pdf/75102-REVISED-PUBLIC-MultisectoralApproachestoNutrition.pdf.

Page $18 / 23$ 
14. Masters WA, Rosettie K, Kranz S, Pedersen SH, Webb P, Danaei G, et al. Priority interventions to improve maternal and child diets in Sub-Saharan Africa and South Asia. Matern Child Nutr. 2018;14(2):1-11.

15. FAO \& WFP. Homegrown School Feeding. Resource Framework. Technical Document. Rome; 2018. Available from: http://www.fao.org/3/ca0957en/CA0957EN.pdf.

16. Bryce J, Coitinho D, Darnton-Hill I, Pelletier D, Pinstrup-Andersen P. Maternal and child undernutrition: effective action at national level. Lancet. 2008;371(9611):510-26.

17. Outes I, Porter C. Catching up from early nutritional deficits? Evidence from rural Ethiopia. Econ Hum Biol. 2013;11(2):148-63.

18. Bundy DAP, de Silva N, Horton S, Patton GC, Schultz L, Jamison DT. Child and adolescent health and development: realizing neglected potential. In: Bundy DAP, de Silva N, Horton S, Jamison DT, Patton GC, editors. Child and Adolescent Health and Development. Third edition. Washington, DC: World Bank; 2017. p. 1-24.

19. Prentice AM, Ward KA, Goldberg GR, Jarjou LM, Moore SE, Fulford AJ et al. Critical windows for nutritional interventions against stunting. Am J Clin Nutr. 2013;97(5):911-8.

20. WFP. A chance for every schoolchild. Partnering to scale up School Health and Nutrition for Human Capital. WFP School Feeding Strategy $2020-2030$. Rome: WFP; 2020. Available from: https://docs.wfp.org/api/documents/WFP-0000112101/download/?_ga=2.117934027.376835949.1580789897391419386.1580789897

21. Wang D, Stewart D. The implementation and effectiveness of school-based nutrition promotion programmes using a health-promoting schools approach: A systematic review. Public Health Nutr. 2013;16(6):1082-100.

22. Aliyar R, Gelli A, Hamdani SH. A Review of Nutritional Guidelines and Menu Compositions for School Feeding Programs in 12 Countries. Front Public Heal. 2015;3(August):1-13.

23. Tette EMA, Enos JY. Effect of the Ghana School Feeding Programme on Nutrient Intake, Nutritional Status and Education of Children: A Review. Asian Journal of Dietetics. 2020;49-57.

24. Kyere P, Veerman JL, Lee P, Stewart DE. Effectiveness of school-based nutrition interventions in sub-Saharan Africa: A systematic review. Public Health Nutr. 2020;23(14):2626-36.

25. Erismann S, Diagbouga S, Schindler C, Odermatt P, Knoblauch AM, Gerold J, et al. School children's intestinal parasite and nutritional status one year after complementary school garden, nutrition, water, sanitation, and hygiene interventions in Burkina Faso. Am J Trop Med Hyg. 2017;97(3):904-13.

26. WFP. State of School Feeding Worldwide. Rome: WFP; 2013. Available from:

https://documents.wfp.org/stellent/groups/public/documents/communications/wfp257481.pdf.

27. Gelli A, Neeser K, Drake L. Home grown school feeding: Linking smallholder agriculture to school food provision. HGSF Working Paper Series \#1. London: Partnership for Child Development. 2010.

28. Fernandes M, Galloway R, Gelli A, Mumuni D, Hamdani S, Kiamba J, et al. Enhancing Linkages between Healthy Diets, Local Agriculture, and Sustainable Food Systems: The School Meals Planner Package in Ghana. Food Nutr Bull. 2016;37(4):571-84.

29. Morgan A, Davies M, Ziglio E, editors. Health assets in a global context: theory, methods, action. Springer Science \& Business Media; 2010.

30. Shrestha RM, Schreinemachers P, Nyangmi MG, Sah M, Phuong J, Manandhar S, et al. Home-grown school feeding: Assessment of a pilot program in Nepal. BMC Public Health. 2020;20(1):1-15.

31. Mensah C. Incentivising smallholder farmer livelihoods and constructing food security through home-grown school feeding: Evidence from Northern Ghana. Brazilian J Int Law. 2018;15(3):491-504.

32. Masset E, Gelli A. Improving community development by linking agriculture, nutrition and education: Design of a randomised trial of " home-grown" school feeding in Mali. Trials. 2013;14(1):1-23.

33. Singh S, Fernandes M. Home-grown school feeding: promoting local production systems diversification through nutrition sensitive agriculture. Food Secur. 2018;10(1):111-9.

34. Mbuya NVN, Atwood SJ, Huynh PN. Persistent Malnutrition in Ethnic Minority Communities of Vietnam: Issues and Options for Policy and Interventions. International Development in Focus. Washington, DC: World Bank; 2019. Available from:

http://documents1.worldbank.org/curated/en/369601561716089327/pdf/Persistent-Malnutrition-in-Ethnic-Minority-Communities-of-Vietnam-Issues-andOptions-for-Policy-and-Interventions.pdf.

35. Kozel V. Well Begun but Not Yet Done: Progress and Emerging Challenges for Poverty Reduction in Vietnam. Equity and Development. Washington, DC: World Bank; 2014. Available from: https://openknowledge.worldbank.org/handle/10986/20074.

36. Ha TTT, Luoh JW, Sheu A, Thuy LT, Yang R. Vegetable Diversity, Productivity, and Weekly Nutrient Supply from Improved Home Gardens Managed by Ethnic Families - a Pilot Study in Northwest Vietnam. Food Ethics. 2019;4(1):35-48.

37. Huong LT, Nga VTT. Nutritional Practices among Ethnic Minorities and Child Malnutrition in Mountainous Areas of Central Vietnam. Food Nutr Sci. 2013;04(01):82-9.

38. Le TT, Le TTD, Do NK, Savvina Nadezhda V, Andrej MG, Nguyen TTT, et al. Ethnic variations in nutritional status among preschool children in northern Vietnam: A cross-sectional study. Int J Environ Res Public Health. 2019;16(21).

39. Government of Vietnam. National Nutrition Strategy 2001-2010. Hanoi; 2001. Available from: https://extranet.who.int/nutrition/gina/sites/default/filesstore/VNM\%202001\%20National\%20nutrition\%20strategy\%202001-2010.pdf.

40. Government of Vietnam. National Nutrition Strategy for 2011-2020, with a vision toward 2030. Hanoi; 2012. Available from: https://extranet.who.int/nutrition/gina/sites/default/filesstore/VNM\%202011\%202.\%20National\%20Nutrition\%20\%20Strategy\%202011-2020.pdf. 
41. Rawat R, Nguyen PH, Ali D, Saha K, Alayon S, Kim SS, et al. Learning how programs achieve their impact: embedding theory-driven process evaluation and other program learning mechanisms in alive \& thrive. Food Nutr Bull. 2013;34(3):S212-25.

42. Herforth A, Harris J. Understanding and applying primary pathways and principles. Brief \#1. Improving Nutrition through Agriculture Technical Brief Series. Arlington, VA: USAID/Strengthening Partnerships, Results, and Innovations in Nutrition Globally (SPRING) Project; 2014. Available from: https://www.spring-nutrition.org/sites/default/files/publications/briefs/spring_understandingpathways_brief_1.pdf.

43. Olney DK, Vicheka S, Kro M, Chakriya C, Kroeun H, Hoing LS, et al. Using program impact pathways to understand and improve program delivery, utilization, and potential for impact of Helen Keller International's Homestead Food Production Program in Cambodia. Food Nutr Bull. 2013;34(2):169-84.

44. Kennedy G, Ballard T, Dop MC. Guidelines for measuring household and individual dietary diversity. Rome: FAO; 2013. Available from: http://www.fao.org/3/i1983e/i1983e00.pdf.

45. Bi J, Liu C, Li S, He Z, Chen K, Luo R, et al. Dietary diversity among preschoolers: A cross-sectional study in poor, rural, and ethnic minority areas of central south china. Nutrients. 2019;11(3):1-12.

46. Tiwari P, Bhat AK, Tikoria J. An empirical analysis of the factors affecting social entrepreneurial intentions. J Glob Entrep Res. 2017;7(1):1-25.

47. Bazeley P. Qualitative data analysis: Practical strategies. Sage; 2013. 472 pages.

48. Gelli A, Masset E, Folson G, Kusi A, Arhinful DK, Asante F, et al. Evaluation of alternative school feeding models on nutrition, education, agriculture and other social outcomes in Ghana: Rationale, randomised design and baseline data. Trials. 2016;17(1).

49. Sumberg J, Sabates-Wheeler R. Linking agricultural development to school feeding in sub-Saharan Africa: Theoretical perspectives. Food Policy. 2011;36(3):341-9.

50. Olney DK, Pedehombga A, Ruel MT, Dillon A. A 2-Year Integrated Agriculture and Nutrition and Health Behavior Change Communication Program Targeted to Women in Burkina Faso Reduces Anemia, Wasting, and Diarrhea in Children 3-12.9 Months of Age at Baseline: A Cluster-Randomized Controlled Trial. J Nutr. 2015;145(6):1317-24.

51. Nordhagen S, Nielsen J, van Mourik T, Smith E, Klemm R. Fostering CHANGE: Lessons from implementing a multi-country, multi-sector nutrition-sensitive agriculture project. Eval Program Plann. 2019;77(November 2018):101695.

52. Schreinemachers P, Ouedraogo MS, Diagbouga S, Thiombiano A, Kouamé SR, Sobgui CM, et al. Impact of school gardens and complementary nutrition education in Burkina Faso. J Dev Eff. 2019;11(2):132-45.

53. Heck S, Campos H, Barker I, Okello JJ, Baral A, Boy E, et al. Resilient agri-food systems for nutrition amidst COVID-19: evidence and lessons from foodbased approaches to overcome micronutrient deficiency and rebuild livelihoods after crises. Food Secur. 2020;12(4):823-30.

54. Benevenuto de Amorim AL, Ribeiro Junior JRS, Bandoni DH. National school feeding program: Strategies to overcome food insecurities during and after the covid-19 pandemic. BRAZILIAN J PUBLIC Adm. 2020;54(4):1134-45.

55. Khan NC, Hoan P Van. Vietnam recommended dietary allowances 2007. Asia Pac J Clin Nutr. 2008;17(SUPPL. 2):409-15.

56. Modjadji P, Molokwane D, Ukegbu PO. Dietary Diversity and Nutritional Status of Preschool Children in North West Province, South Africa: A Cross Sectional Study. Children. 2020;7(10):174.

57. WFP. Cost-Benefit Analysis of the School Meals Programmes in Lao May 2018. Vientiane; 2018. Available from: https://docs.wfp.org/api/documents/WFP-0000105403/download/?_ga=2.233077720.711786554.1610700378-710191333.1550491864.

58. Nordhagen S, Thiam K, Sow S. The sustainability of a nutrition-sensitive agriculture intervention: a case study from urban Senegal. Food Secur. 2019;11(5):1121-34.

59. Roche ML, Sako B, Osendarp SJM, Adish AA, Tolossa AL. Community-based grain banks using local foods for improved infant and young child feeding in Ethiopia. Matern Child Nutr. 2017;13(2):1-15.

60. Sako B, Leerlooijer JN, Lelisa A, Hailemariam A, Brouwer ID, Tucker Brown A, et al. Exploring barriers and enablers for scaling up a community-based grain bank intervention for improved infant and young child feeding in Ethiopia: A qualitative process evaluation. Matern Child Nutr. 2018;14(2):1-11.

61. Bernet T, Kurbanalieva S, Pittore K, Zilly B, Luttikholt L, Eyhorn F, et al. Nutrition-Sensitive Agriculture Interventions in Mountain Areas-Lessons Learned From a 5-Country Project to Upscale Best Practices. Mt Res Dev. 2018;38(4):278.

62. Ogoye-Ndegwa C, Abudho D, Aagaard-Hansen J. "New learning in old organisations": Children's participation in a school-based nutrition project in western Kenya. Dev Pract. 2002;12(3-4):449-60.

63. Muehlhoff E, Wijesinha-Bettoni R, Westaway E, Jeremias T, Nordin S, Garz J. Linking agriculture and nutrition education to improve infant and young child feeding: Lessons for future programmes. Matern Child Nutr. 2017;13(September 2016):1-12.

64. Nielsen JN, Olney DK, Ouedraogo M, Pedehombga A, Rouamba H, Yago-Wienne F. Process evaluation improves delivery of a nutrition-sensitive agriculture programme in Burkina Faso. Matern Child Nutr. 2018;14(3):1-10.

\section{Figures}




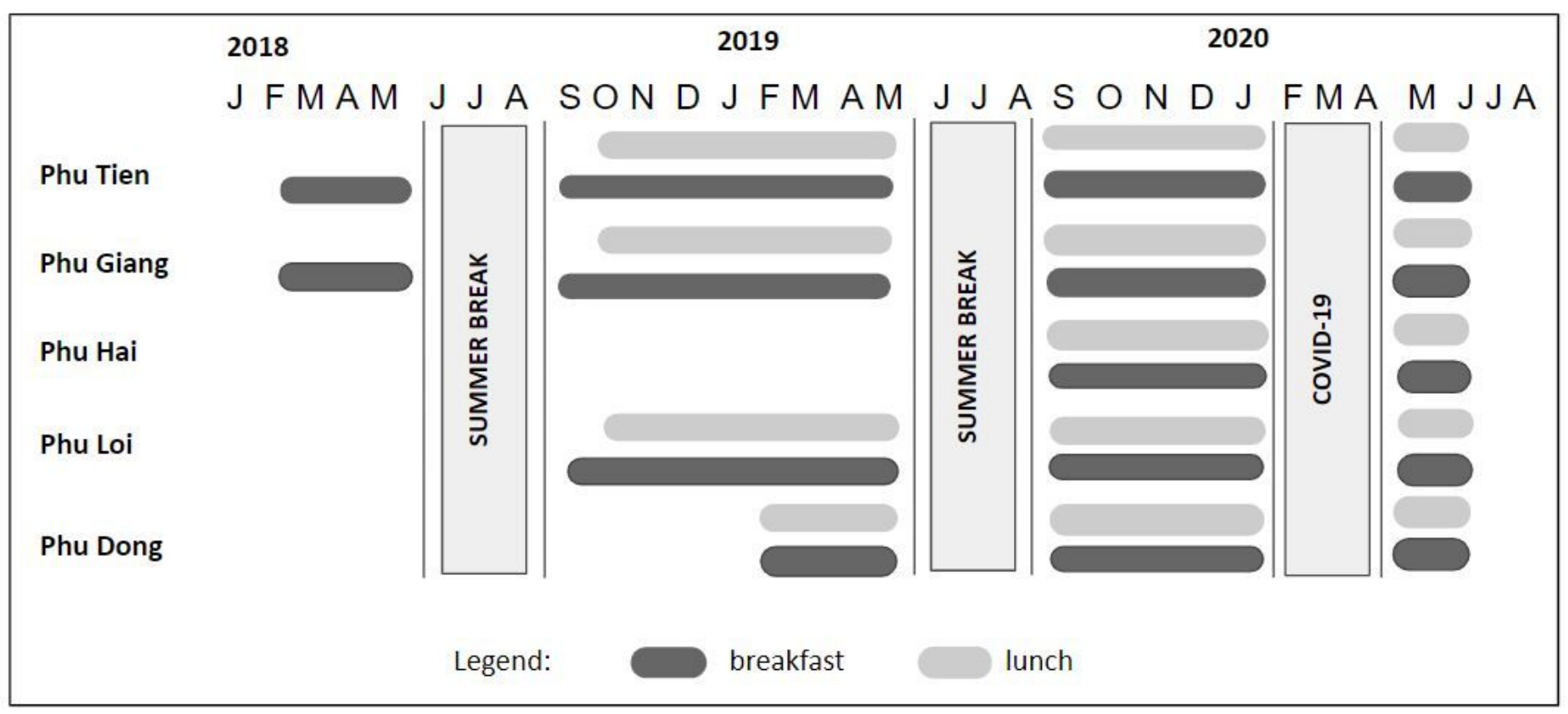

Figure 1

Implementation timeline of HGSF component in Phu Mo villages

Inputs

\begin{tabular}{|l|}
\hline Scientific partnership: \\
- Medical Committee \\
Netherlands-Vietnam \\
- Hue University of \\
Agriculture and \\
Forestry \\
- Hue University of \\
Medicine and \\
Pharmacy \\
- Vrije Universiteit \\
Amsterdam \\
\hline
\end{tabular}

\begin{tabular}{|l|l|}
\hline \hline $\begin{array}{l}\text { Implementation } \\
\text { partnership: } \\
\text { - MCNV } \\
\text { - Provincial health } \\
\text { department } \\
\text { - District ariculture }\end{array}$ & $\begin{array}{l}\text { Household heads } \\
\text { responsible for groups } \\
\text { selected and trained }\end{array}$ \\
\hline \hline $\begin{array}{l}\text { Measuring scales and } \\
\text { communication material } \\
\text { provided }\end{array}$ \\
\hline
\end{tabular}

(t)

departments

- Commune health

station (CHS)

- Nursery schoo

teachers (NST)

- Micro-entrepreneurs

(ME)

- Village health workers

(VHW)

- Household groups

\begin{tabular}{|l|}
\hline $\begin{array}{l}\text { Commune agricultural } \\
\text { staff trained on HFP and } \\
\text { intercropping models }\end{array}$ \\
\hline \hline $\begin{array}{l}\text { Financial \& material } \\
\text { inputs for HFP and } \\
\text { intercropping models }\end{array}$ \\
\hline $\begin{array}{l}\text { CHS staff and VHW } \\
\text { trained on nutrition } \\
\text { counselling, growth } \\
\text { monitoring, disease } \\
\text { prevention, hygiene \& } \\
\text { breastfeeding practices }\end{array}$ \\
\hline \hline Household groups set up \\
\hline \hline $\begin{array}{l}\text { Household heads } \\
\text { responsible for groups } \\
\text { selected and trained }\end{array}$ \\
\hline \hline $\begin{array}{l}\text { Measuring scales and } \\
\text { communication material } \\
\text { provided }\end{array}$ \\
\hline
\end{tabular}

ME selected and trained

on food preparation,

School meal menus and

cooking equipment

provided to ME

NST trained on nutrition, feeding, WASH practices

School meal subsidy

(NSA program, parents)

government) hygiene, food safety
Process

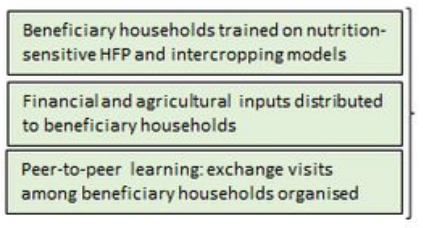

Mobile medical check up and counselling of parents and pregnant women for detection and treatment of severely malnourished children

Nutrition counselling by VHW and staff of CHS to beneficiary households

Monthly household group meetings organised, including: growth monitoring of CU5, cooking demonstrations, knowledge sharing on caring, feeding and health

practices, peer-to-peer support and learning

Procurement of ingredients from external and home-grown sources to produce nutritious meals for the nursery schools but also for other buyers in the communities

Regular meeting among NST, ME, parents and program implementers to monitor the implementation of the school feeding

Mothers volunteering in the school meal component trained by NST on nutrition, feeding and WASH practices
Outputs

\begin{tabular}{|l|}
\hline $\begin{array}{l}\text { HFP and intercropping models } \\
\text { implemented }\end{array}$ \\
\hline \hline $\begin{array}{l}\text { Increased knowledge and skills on } \\
\text { nutrition-sensitive agricultural } \\
\text { models }\end{array}$ \\
\hline \hline $\begin{array}{l}\text { Increased community-level } \\
\text { production of and access to } \\
\text { nutrient-rich foods (supply) }\end{array}$ \\
\hline
\end{tabular}

nutrient-rich foods (supply)

\begin{tabular}{|l|}
\hline $\begin{array}{l}\text { Increased awareness and } \\
\text { knowledge of parents and } \\
\text { community members on causes } \\
\text { and impacts of malnutrition }\end{array}$ \\
\hline Increased knowledge and skills of \\
parents and pregnant women in \\
good practices for nutrition, \\
caring and feeding, hygiene, \\
breastfeeding and disease \\
prevention \\
\hline
\end{tabular}

prevention

\begin{tabular}{|l|}
\hline $\begin{array}{l}\text { HGSF implemented in all } 5 \\
\text { nursery schools }\end{array}$ \\
\hline \hline 4 ME established to supply meals \\
to 5 schools
\end{tabular}
home-grown nutrientrich fruits, vegetables and animal foods

Increased attendance rate at nursery schools

Increased consumption of nutritious food by nursery school children

Adoption of schoolmeal relevant practices
Impacts

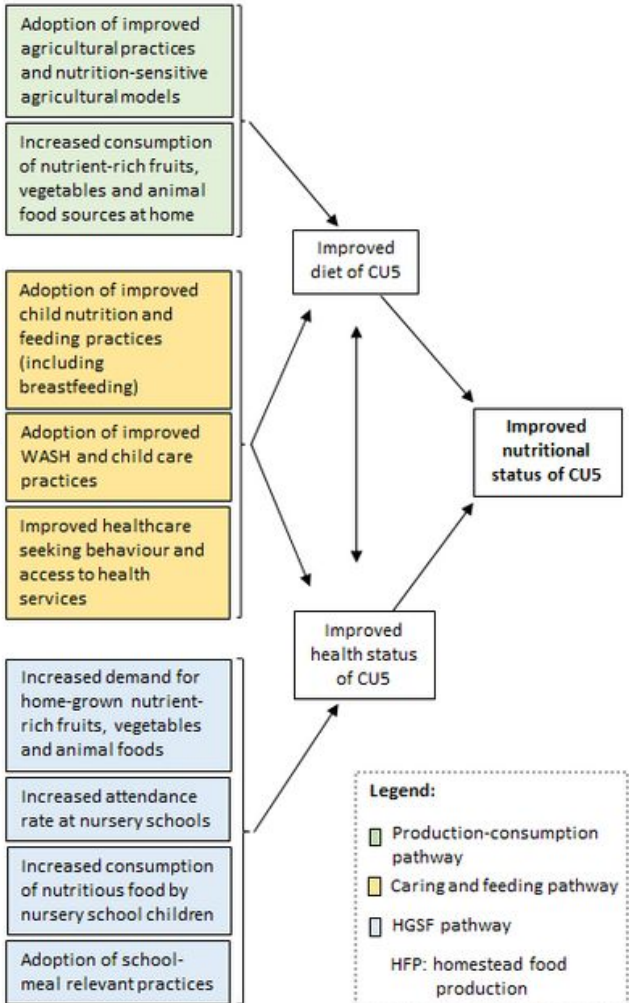

Figure 2

Ex-ante program theory of change 


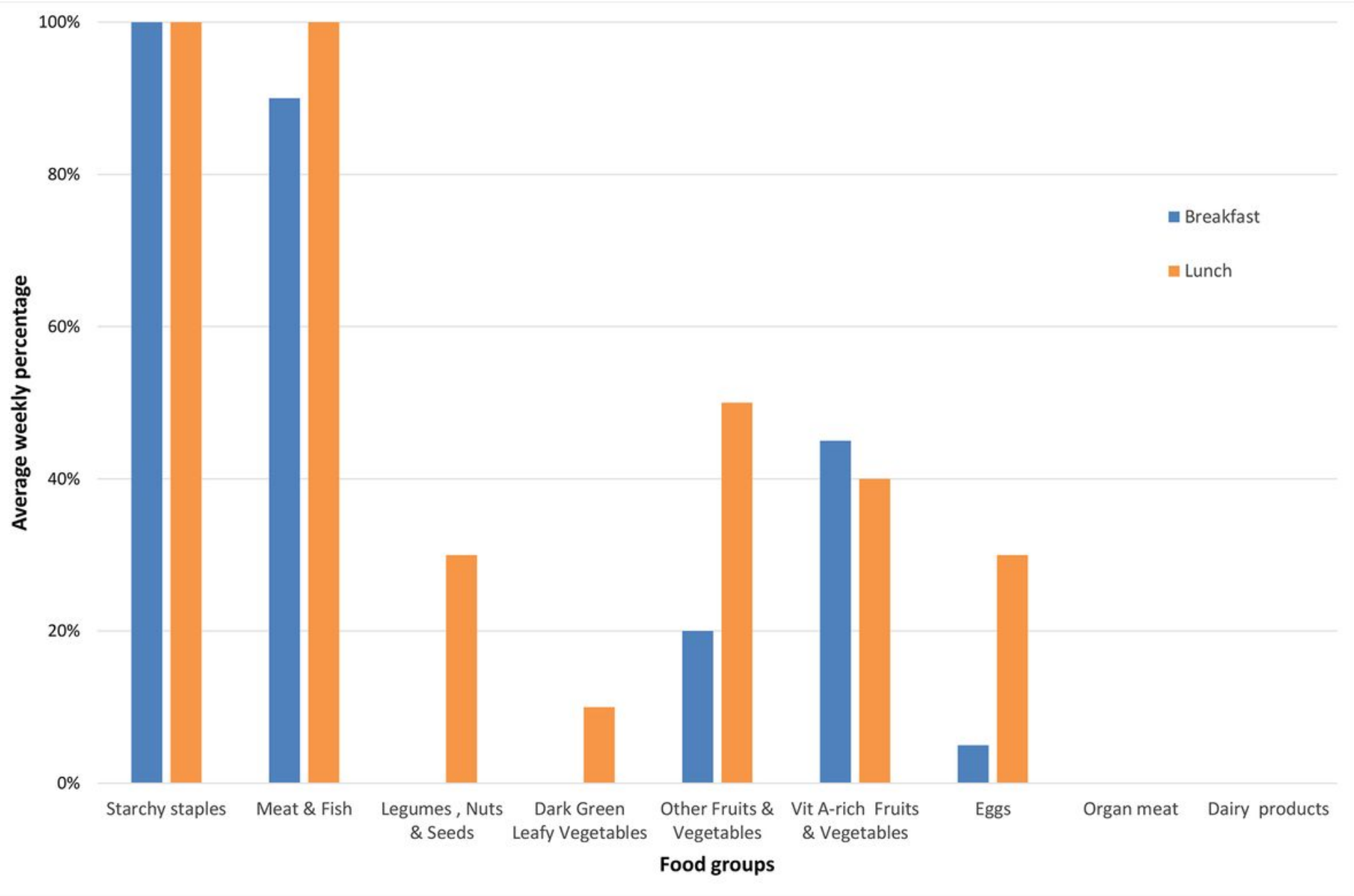

\section{Figure 3}

Inter-food group diversity - average percentage of food groups included in weekly school meals 


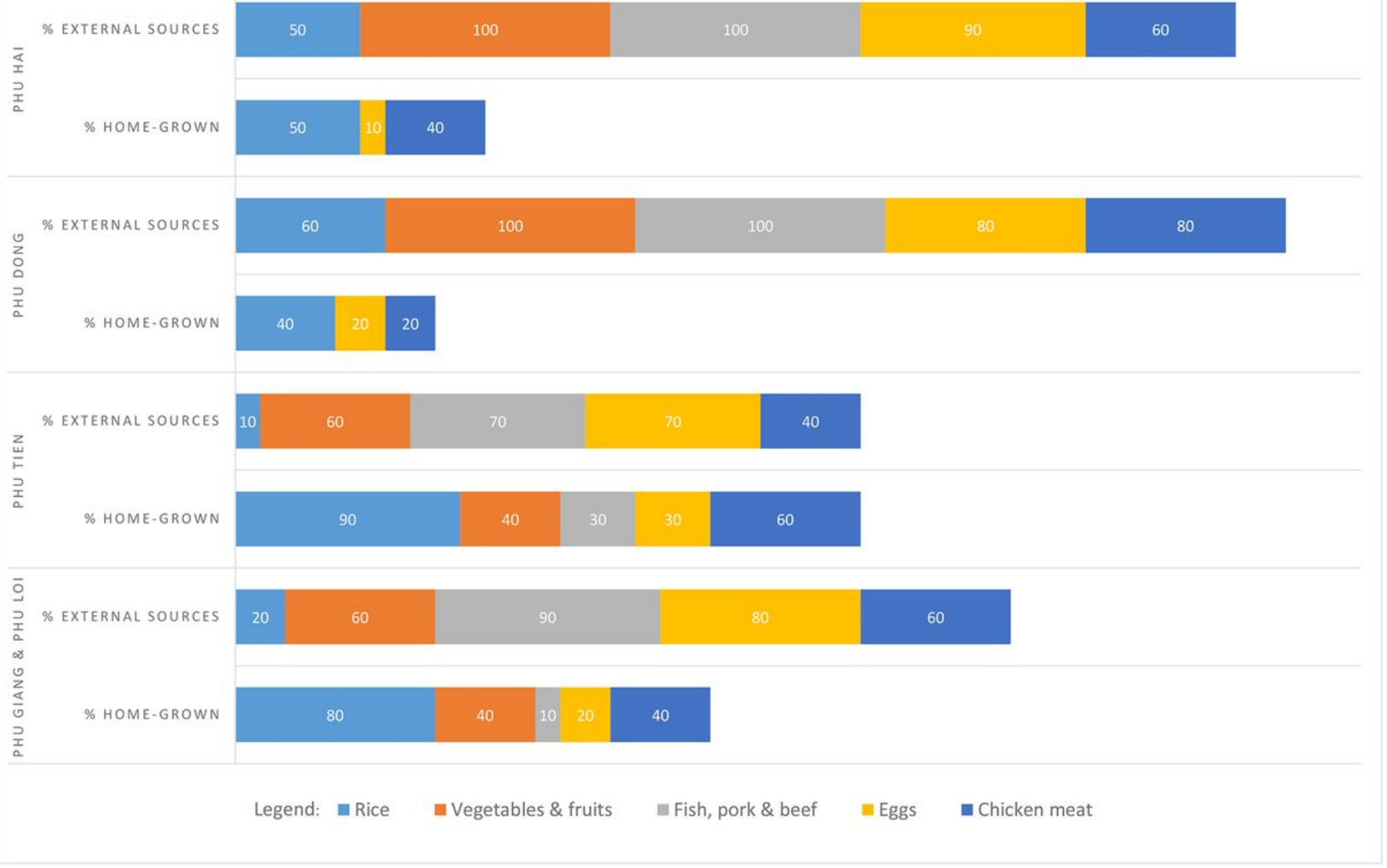

\section{Figure 4}

Overview of food sources for Phu Mo school meals 